\title{
Developmental Trajectories of Event Centrality and Socio-Emotional Well-Being after Transition to High School
}

\author{
Shuhei limura*1 \\ ${ }^{1}$ The University of Tokyo, Japan Society for the Promotion of Science
}

${ }^{*}$ Corresponding author information: Corresponding concerning this article should be addressed to Shuhei limura, The University of Tokyo, 7-3-1 Hongo Bunkyo-ku, Tokyo 113-0033, Japan. (e-mail: iimurashuhei@gmail.com)

\begin{abstract}
:
Although the transition from junior high or middle school to high school can be a stressful turning point for youth socio-emotional development, the role of individual differences in susceptibility to the transition in adolescents' socio-emotional well-being remains unclear. The current study examined the developmental relation between how central the high school transition is to a student's identity or life course (i.e., event centrality) and socioemotional well-being after transition. High school students, including cohorts in 10th to 12th grade $\left(n=2,265, M_{\text {age }}\right.$ at Time $1=15.9$ years, $S D_{\text {age }}=0.9$ years $)$, participated in a four-wave longitudinal survey for a year, and completed questionnaires assessing event centrality and socio-emotional well-being. Latent growth curve modeling revealed individual differences in the developmental trajectory of event centrality regarding high school transition across the 10th to 12th grades. Increase in the centrality of transition was closely associated with improvement in socio-emotional well-being for each grade progression. Findings highlight the value of examining individual differences in the degree to which the school transition becomes a turning point in a student's identity or life course.
\end{abstract}

\section{Keywords:}

school transition, event centrality, socio-emotional well-being, adolescence, latent growth curve model

\section{Data availability statement:}

The data that support the findings of this study are available from the corresponding author upon reasonable request.

\section{Acknowledgements:}

This study was funded by JSPS KAKENHI Grant Number JP16J01937 and JP19J00270.

\section{Citation:}

limura, S. (2020) Developmental Trajectories of Event Centrality and Socio-Emotional Well-Being after Transition to High School. British Journal of Developmental Psychology.

This document is the author's final accepted version of the journal article. There may be differences between this version and the published version. 
Developmental Trajectories of Event Centrality and Socio-Emotional Well-Being after

\section{Transition to High School}

Developmental researchers may intuitively assume individual differences in the influence of the transition from junior high school to high school on youth socio-emotional development. However, current knowledge on the role of susceptibility to school transition in the development of socio-emotional well-being is largely limited. The present study aimed to provide evidence that individual differences in how central the high school transition is in becoming a turning point for a student's identity or life course are closely related to the development of the Japanese student's socio-emotional well-being.

The transition to high school is known as a predictable and normative life event in several countries, including the United States (Benner, 2011) and Japan (Iimura \& Taku, 2018). The timing of transition from junior high school (or middle school) to high school depends on the country's educational system. For example, most Japanese students spend six years in elementary school, three years in junior high school, and three years in high school (also called the 6-3-3 system); students can also choose the 6-6 system, but those who do so represent a minority (for details, see Supplementary Materials Figure S1). Although educational systems vary by country, the school transition in common occurs during developmental stages when most students are also experiencing physical and psychological changes dynamically (Berenbaum, Beltz, \& Corley, 2015; Lord, Eccles, \& McCarthy, 1994). Changes in school environments, therefore, can be cumulatively stressful turning points for many adolescents under unstable conditions related to pubertal development.

Indeed, in systematic reviews of research on the high school transition, many scholars have observed disruptions in student functioning across developmental domains (e.g., Benner, 2011). For example, students experience declines in self-esteem (Barber \& Olsen, 2004), social support (Newman, Newman, Griffen, O’Connor, \& Spas, 2007), and sense of school belonging (Benner \& Graham, 2009) on average; they also express depression (Newman et al., 2007), anxiety (Benner \& Graham, 2009), and loneliness (Benner, Boyle, \& Bakhtiari, 2017) after the transition to high school, suggesting that some students cognitively struggle with the requisite transitional tasks to adjust to their new school settings (Iimura \& Taku, 2018). According to stage-environment fit theory (Eccles et al., 1993), these declines in socio-emotional well-being may be the result of the potential mismatch between the student's developmental status and 
school environment. Most studies have reported that being of a racial/ethnic minority may be a robust factor that contribute to the decrease in socio-emotional well-being (e.g., Benner \& Graham, 2007), but the effects of other covariates, including gender, currently seem to be inconsistent across studies.

To identify the dominant covariates that strongly contribute to youth socio-emotional development after the high school transition, we may need to focus on the student's subjective appraisal of their experience of the transition. Facchin, Margola, Molgora, and Revenson (2014), for instance, conducted a school-based intervention of expressive writing, and they found that students who write about the positive aspects of high school transition in relation to benefits and advantages developed a positive self-conception compared with those assigned to other conditions (i.e., standard expressive writing and factual writing). This finding is significant because it suggests individual differences in the subjective appraisal of the school transition, which can be transformed and relate to youth socio-emotional development. Nevertheless, knowledge as to how the student's subjective appraisal of high school transition relates to their status of adaptation in high school is limited.

The individual's subjective appraisals of stressful life transition can be captured by the concept of event centrality. The core idea of event centrality is that "a memory for a stressful event forms a reference point for personal identity and for the attribution of meaning to other experiences in a person's life" (Berntsen \& Rubin, 2006, p. 220). Personal memories of a momentous event, from normative stressful life events to traumatic events, are characterized by importance, definiteness, and brevity, which are likely to function as a salient turning point that alters or redirects the life course (e.g., Pillemer, 1998). Such memories become reference points when persons form their identity. In the context of the current study, for example, some adolescents would recognize themselves as "a high school student," not "a junior high school student," to recall their experience of the high school transition.

To measure the degree to which a momentous event, including life transition, is central to an individual's identity or life course, the Centrality of Event Scale can be used (Berntsen \& Rubin, 2006). This scale is composed of a series of items that reflect whether an event had become a reference point for the way a person understands their self and the world in their life, whether an event had contributed a central component to individual identity, and whether an event had altered a person's life course. Individual differences in event centrality are reported in 
several studies (for a review, see Gehrt, Berntsen, Hoyle, \& Rubin, 2018).

Iimura and Taku (2018) reported the relation between centrality of the high school transition and the student's functioning. They demonstrated that students who recognize the transition as a salient turning point for their identity or life story show positive developmental changes from shortly before to shortly after the transition in relation to others, future time perspectives, personal strength, spirituality, and appreciation of life. These changes can occur because students with high event centrality have clearly understood the association between themselves and the high school transition, for example, in the form of importance of school life; thus, they can independently thrive in their high school life.

As noted above, prior findings suggest that individual differences in event centrality are related to youth socio-emotional development following the high school transition. However, early reports have two limitations. First, the relation between the plasticity of event centrality and development of socio-emotional well-being remains unexamined. Second, the longitudinal role of event centrality across high school life continues to be unknown owing to the short time interval of surveys. Although prior research, conducted by Facchin et al. (2014), suggests that it is possible to change a student's event centrality regarding high school transition, no such evidence has been explored. Taken together, to promote the current understanding of the relation between individual differences in event centrality and socio-emotional well-being after transition, studies need to expand the time span for surveys and capture changes in event centrality of the transition.

\section{Overview of the Current Study}

To clarify the aforementioned two issues, the current study, using a Japanese sample of 10th- to 12th-grade cohorts, aimed to explore the developmental trajectories of event centrality regarding the high school transition and its association with changes in socio-emotional wellbeing. To our knowledge, although there are no international comparative developmental researches on high school transition, Japan's unique educational system, such as the high school entrance exam, may cause individual differences in the event centrality and socio-emotional adjustment after the transition, in addition to simply changes in school environment (e.g., Iimura, 2018; Iimura \& Taku, 2018). Specifically, unlike the high school transfer system in many Western countries, the majority of students in Japan (i.e., 6-3-3 system) have to pass an achievement-based selection test to enter the high school of their choice. Each high school has a 
different level of difficulty in enrolling, and students cannot enroll in high school unless they exceed the high school's required test score. In that case, students will go to a different high school than they want; on the other hand, students may be able to enter the high school they want, but the school environment may be different from what they expected. Therefore, physical and psychological gaps resulting from such transitions may affect the development of event centrality and socio-emotional adjustment after high school transition.

The present study also examined the impact of covariates, including the type of high school (6-3-3 system vs. 6-6 system), and type of choice (number one choice vs. other), and gender (boy vs. girl) on development of event centrality and socio-emotional well-being following the school transition. Empirical studies in Japan to date have been limited, but as mentioned above, the impact on the socio-emotional development of students will differ depending on whether students are transferred to high school under the 6-6-3 system, which requires entrance examinations for high school, or the 6-3 system, which does not require it. Similarly, whether a student entered the high school of his or her first choice may partly explain the development of event centrality and socio-emotional well-being. Additionally, from the perspective of biological development, gender differences in pubertal development are prominent among junior and high school students (e.g., girls mature faster than boys in general; Berenbaum et al., 2015), and the association with socio-emotional development such as depression has been pointed out (e.g., Ge, Conger, \& Elder Jr, 2001); therefore, gender was included in the covariates in this study.

\section{Methods}

\section{Participants and Procedure}

We conducted the year-long, four-wave longitudinal study, named Adolescent Development during Transition to High School Project, in five high schools in Tokyo. Of the five schools, two were integrated junior and senior high schools (six-year system), and three were normative high schools (three-year system). Supplementary Figure S1 depicts the relationship between the Japanese school system and the current participants. The first survey was conducted in July, about three months after the start of a new school term in Japan. Thereafter, surveys were conducted about every three months. Before the start of each survey, informed consent was obtained from both students and parents. There was no reward for research 
cooperation. All procedures in the current study were approved by the institutional review board of Chuo University (approval number: 2017-4).

The interval between the surveys was three months. At the first measurement, 2,265 students (1,071 girls, $M_{\mathrm{age}}=15.9$ years, $S D_{\mathrm{age}}=0.9$ years $)$ who attended high school, including cohorts in the 10th to 12th grades (i.e., first to third year of high school), completed questionnaires assessing event centrality and socio-emotional well-being. Data were subsequently collected from 2,190 students in Time 2 (1,112 girls, $M_{\text {age }}=16.3$ years, $S D_{\text {age }}=1.0$ years); 1,493 students in Time 3 (755 girls, $M_{\text {age }}=16.2$ years, $S D_{\text {age }}=0.8$ years); and 2,463 students in Time 4 (1,228 girls, $M_{\text {age }}=16.6$ years, $S D_{\text {age }}=0.9$ years $)$. At each time point, we recruited students who had not participated in the previous survey. Finally, 1,023 students participated in all of the surveys. Little's missing completely at random (MCAR) test indicated that missing values were MCAR for the 10th grade $\left(\chi^{2}(193)=207.69, p=.222\right)$ but not for the 11 th $\left(\chi^{2}(147)=188.32, p=.012\right)$ and 12th grades $\left(\chi^{2}(147)=205.41, p<.001\right)$.

\section{Measures}

Event centrality. To measure how central the transition to high school was to a student's identity and life story, we used the seven-item Japanese version of the Centrality of Event Scale (Naka, 2008). This scale is a widely used measure of event centrality with excellent psychometric properties (Berntsen \& Rubin, 2006). Example items of this scale are "the event has colored the way I think and feel about other experiences" and "I often think about the effects this event will have on my future." Items were scored on a six-point scale, ranging from 1 (totally disagree) to 6 (totally agree) points. For the current sample, these items showed strong internal consistency over the four time-point surveys; Cronbach's alpha was .90 for Time 1,.93 for Time 2, .94 for Time 3, and .94 for Time 4. The autocorrelation coefficient between surveys was $r=.57(p<.001)$ on average.

Socio-emotional well-being. Students rated their socio-emotional well-being in the last two weeks using the Japanese version of the World Health Organization (WHO)- Five WellBeing Index (WHO-5-J; Awata et al., 2007). This index includes five items, such as "I have felt cheerful and in good spirits" and "I have felt calm and relaxed." Students scored them on a sixpoint scale, ranging from 1 (at no time) to 6 (all of the time) points. Cronbach's alpha for Time 1 to Time 4 was $.90, .93, .94$, and .94 , respectively, indicating good internal consistency. The average autocorrelation coefficient (i.e., rank order stability) from Time 1 to Time 4 was $r=.46$ 
$(p<.001)$.

Covariates. We measured three time-invariant covariates as follows. (a) Students reported the type of school to which they belong. School type was coded as 0 for integrated junior and senior high school and 1 for normative high school. In Japan, junior high school students need to pass entrance examinations to enter normative high school, whereas students attending integrated junior and senior high schools do not need it. Therefore, the degree of change in school environment following transition is greater in students who enter normative high schools compared with those who belong to integrated schools in general. (b) Students also answered whether the high school they entered was their number one choice or not, given that Japanese students are not always able to enter the school they desire because of the selection by entrance examinations as noted above. This item was coded as 0 for number one choice and 1 for others. (c) Finally, students reported their gender (boys were coded as 0, girls, as 1).

\section{Statistical Analysis}

To examine developmental trajectories in event centrality and socio-emotional well-being after the transition to high school, we conducted latent growth curve modeling (LCM; for details, see Duncan, Duncan, Stryker, \& Alpert, 1999; Figure 1) in two steps.

First, we used univariate multi-group LCMs that assumed the same model for each grade (i.e., 10th, 11th, 12th grades), with estimation of Full Information Maximum Likelihood, to reveal the developmental trajectories of event centrality and socio-emotional well-being separately. We identified the optimal shapes of trajectories based on the Akaike Information Criterion (AIC) and delta chi-square $\left(\Delta \chi^{2}\right)$ difference test for three types of LCMs: model with no slope, model with linear slope, and model with quadratic slope. The model with no slope indicated that developmental trajectories were constant over time (i.e., stable); no latent variable for slope was included in this model. In the model with linear slope, developmental trajectories showed linear changes over time. The model with quadratic slope assumed that longitudinal data followed quadratic trajectories. To express these trajectories, path coefficients from latent variables for slope to observed variables at each occasion were fixed to $0,1,2$, and 3 in the linear slope and $0\left(=0^{2}\right), 1\left(=1^{2}\right), 4\left(=2^{2}\right)$, and $9\left(=3^{2}\right)$ in the quadratic slope models. The fixed effects, representing the means of the intercept and slope, indicate overall trajectories of event centrality and socio-emotional well-being; the random effects, representing the variances of the intercept and slope, capture the between-person process. To compare the best models, the goodness of fit 
was interpreted as follows: The lower the Bayesian information criterion (BIC) and Akaike information criterion (AIC), the better the model. If the $\Delta \chi^{2}$ difference test is significant, it supports the alternative model (e.g., a model with linear slope) rather than the baseline model (e.g., a model without slope).

Second, we conducted bivariate multi-group LCMs with time-invariant covariates based on the models specified in the first step, to examine relations between changes in event centrality and socio-emotional well-being. As illustrated in Figure 1, this model estimated covariance between intercept and slope for event centrality and socio-emotional well-being (paths A-F). Effects of time-invariant covariates, including gender, type of school, and type of choice, on intercept and slope were also estimated (paths a1-c4).

Model fitting was evaluated based on multiple criteria, including comparative fit index (CFI), root mean square error of approximation (RMSEA), and standardized root mean square residual $($ SRMR), with CFI $>.90$, RMSEA $<.08$, SRMR $<.80$ indicating acceptable model fit (Schermelleh-Engel, Moosbrugger, \& Müller, 2003). Analyses were conducted using R ver. 3.4.4. (R Development Core Team, 2017) and "lavaaan" package (Rosseel, 2012).

[Figure 1]

\section{Results}

\section{Development of Event Centrality}

Table 1 shows the means and standard deviations for event centrality. The intraclass correlation coefficient (ICC) indicated moderate test-retest reliability over the four time points $(\mathrm{ICC}=.58,95 \% \mathrm{CI}[.55, .61], p<.001)$. In addition, the ICC at the class level was $0.02 \sim 0.03$ ( $p$ s $<.002$ ) across occasions. The longitudinal factorial invariance (Widaman, Ferrer, Conger, 2010) test confirmed that the Centrality of Event Scale measured the same factor structure over four time points (see Supplementary Materials Table S1).

The AIC and $\Delta \chi^{2}$ difference tests supported that the model with a linear slope was best fitted to capture the mean-level developmental trajectories of event centrality after school transition (Table 2). The model with linear slope showed a good fit to data: CFI $=0.98$, RMSEA $=0.06, \mathrm{SRMR}=0.04$.

\section{[Table 1] [Table2]}

Table 3 shows the estimated growth parameters of univariate multi-group LCMs (see 
also Appendix Figure A1). For all grades, event centrality increased over about a year on average (i.e., fixed effects), but the coefficients were extremely small (mean slope $<0.06$, $p$ s <.003). Variances of intercept and slope (i.e., random effects) were significant for all grades, suggesting individual differences in scores at Time 1 and subsequent changes.

[Table 3]

\section{Development of Socio-Emotional Well-being}

Descriptive statistics for socio-emotional well-being are presented in Table 1. The ICC for socio-emotional well-being was somewhat low, suggesting that intra-individual variation was relatively large over the four-time points $(\mathrm{ICC}=0.47,95 \%[.44, .50], p<.001)$. At the class level, the ICC was $0.02 \sim 0.06$ ( $p$ s <.001) across occasions. The factor structure of socioemotional well-being measured by the WHO-5-J was supported to measure invariant over four time points (see Supplementary Materials Table S2).

As presented in Table 2, results showed that the model with linear slope was the most optimal compared with the models with no slope and with quadratic slope. The model with linear slope indicated an acceptable fit to the data: $C F I=0.94$, RMSEA $=0.08$, SRMR $=0.06$.

As shown in Table 3 (see also Appendix Figure A1), mean slopes (i.e., fixed effects) were significant for all grades, but the coefficients were extremely small for the 10th and 11th grades (mean slope $<.05, \mathrm{ps}<.012$ ). In contrast, the degree of change was relatively large for the 12th grade (mean slope $=.17, p<.001)$, implying that, on average, their socio-emotional wellbeing positively changed toward graduation. Although slope variance (i.e., random effects) was significant for only the 10th grade, individual differences in the intercept were found for all grades.

\section{Associations between Event Centrality and Socio-Emotional Well-Being}

Results showed that bivariate multi-group LCMs fitted the data well: CFI =0.97, RMSEA $=0.04 . S R M R=0.04$. As illustrated in Figure 2, we estimated the correlation coefficients between intercepts and slopes for event centrality and socio-emotional well-being. The intercept of event centrality was positively associated with that of socio-emotional wellbeing for all grades $(r=.52-.58, p s<.001)$, suggesting that students who recognized the high school transition as an important turning point for their own identity or life story were likely to report a good status of socio-emotional well-being at Time 1. Results also showed positive relations between changes in event centrality and socio-emotional well-being for the 10th $(r$ 
$=.63, p<.001), 11$ th $(r=.78, p=.097)$, and 12th graders $(r=.59, p<.001)$. Students who reported increased event centrality regarding the high school transition improved their socioemotional well-being from Time 1 to Time 4. For the 10th graders, the intercept of socioemotional well-being negatively related to the slope of event centrality, but the effect size was low $(r=-.18, p=.026)$.

\section{[Figure 2]}

Effects of covariates on intercepts and slopes. We also estimated the effects of timeinvariant covariates on the intercepts and slopes of event centrality and socio-emotional wellbeing (Table 4). For the 10th graders, no effects of covariance were found. For the 11th graders, girls were higher than boys in the intercept of event centrality $(b=0.26, S E=0.07, p<.001)$, whereas the degree of changes in event centrality was greater in boys than girls $(b=-0.08, S E=$ $0.02, p=.005)$. For the 12th graders, boys' socio-emotional well-being was higher than girl's in Time $1(b=-0.22, S E=0.09, p=.018)$. In addition, students who entered their first-choice high school had high event centrality $(b=-0.30, S E=0.11, p=.008)$ and socio-emotional well-being $(b=-0.31, S E=0.11, p=.004)$ compared with those who did not. As additional information, the results of a measurement invariance test between grades in the conditioned LCMs were provided in the Supplementary Materials Table S3.

[Table 4]

\section{Discussion}

Although development researchers have assumed that susceptibility to school transition varies among students, no previous study has directly described the developmental nature of such individual differences and their role for socio-emotional well-being during a student's school life. The current research was the first large-scale longitudinal study that revealed the relation between event centrality and socio-emotional well-being after the transition to high school. The results showed developmental diversity across the 10th to 12th grades in trajectories of event centrality regarding the transition to high school (see Table 2). Our findings also indicated that increased centrality of the transition was positively associated with improvement of socioemotional well-being for 10th and 12th graders (see Figure 2). Consequently, the current study provided the first empirical evidence regarding this topic. To shed further light on the relation between school transition and adjustment, future studies should assume individual differences in 
the degree to which the school transition becomes a turning point in a student's identity or life course.

Although the results showed positive changes in the centrality of the transition in all grades on average, we should interpret these findings with caution. It was almost stable because the estimated mean slope parameters were extremely small. Moreover, it should be noted here that individual differences (i.e., random effects) in the initial value and development of event centrality were clearly apparent, as indicated by parameters regarding variance. Although the shape of trajectory has not been examined, with most researchers having assessed event centrality using cross-sectional design (for a review, see Gehrt et al., 2018), our findings demonstrated that plasticity may remain in the development of event centrality after high school transition. In other words, the relationship between event centrality regarding high school transition and students' socio-emotional well-being can change over time.

Additionally, we would like to emphasize two findings regarding individual differences in socio-emotional well-being to promote the current understanding of youth development after school transition as follows. First, significant variance in intercepts was shown in all grades, suggesting that the status of socio-emotional well-being clearly differed among students relatively soon after entering high school. In this regard, both the mean and variance should be considered to capture socio-emotional well-being after the school transition, which may be useful for intervention and education. Second, Japanese students in the 12th grade (i.e., those who are spending their final year of high school) showed increased socio-emotional well-being toward graduation. This finding was in contrast to a study involving a high proportion of ethnic minority students conducted in the United States that reported increasing depression and loneliness from entering to graduating high school (Benner \& Graham, 2009). This possibility might be influenced by cultural factors. Unlike high schools in the United States, the student population of Japanese high school has very little ethnic diversity. For example, the Japanese government reported that fewer than 3,000 students use primary languages other than Japanese in 2016 (Ministry of Education, Culture, Sports, Science, and Technology in Japan, 2017).

Therefore, the difficulties associated with the high school transition experienced by race or ethnic minority adolescents in the United States (e.g., Benner \& Graham, 2009) are rarely addressed in Japanese high schools, where the majority of students are Japanese nationals.

Meanwhile, our findings were interestingly similar to a study in Germany that showed 
students taking their final exam to enter university reported increased conscientiousness and achievement behavior and decreased neuroticism toward graduation (Bleidorn, 2012). Similar to the German study, most of the Japanese 12th-grade students in the current study took exams to enter university between Times 3 and 4 and many of them had finished taking the exams at Time 4. From these common points between Germany and Japan, the clear goal after graduation (e.g., taking exams and entering university) may enhance, on average, a student's socio-emotional well-being right before graduation (e.g., Iimura, 2018).

Our findings also demonstrated the strong relation between event centrality and socioemotional well-being across all grades; especially, the intercept-intercept and slope-slope associations were remarkable. Specifically, the intercept of event centrality was positively correlated with the intercept of socio-emotional well-being $(r>.52)$, and the slope of event centrality was related to the slope of socio-emotional well-being $(r>.59)$. Thus, the event centrality of the high school transition may play an important role in the positive development of socio-emotional well-being in a student's life. This implication corresponds with some findings on student functioning following the high school transition (e.g., Facchin et al., 2014; Iimura \& Taku, 2018). As Facchin et al. (2014) reported, for example, a school-based expressive writing intervention that allows students to describe the benefit of school transition can be an effective method to increasing the event centrality of the transition, leading to enhanced socio-emotional well-being.

Although limited to the 11th grade, we found gender differences in event centrality: the degree to which high school transition contributed to one's identity or life story was higher in girls compared with boys. This finding was consistent with a meta-analytic study (Gehrt et al., 2018) that examined the correlation between the Centrality of Event Scale and gender, in which females have slightly higher scores $(r=.11)$. Research on event centrality has pointed out that females having more detailed emotional memories may be the cause of gender differences (e.g., Boals, 2010; Gehrt et al., 2018). However, the effect size of gender was small in both previous research and the current study. Therefore, the role of gender differences in event centrality should not be overestimated; rather, individual differences should be given focus.

\section{Limitations and Implications}

Our findings promote further understanding of adolescent development following the 
transition to high school. Nonetheless, several limitations should be considered. First, our results might be dependent on ethnicity and cultural factors, given the use of a Japanese sample and system of education; thus, future research using other samples is required, to replicate and validate our findings. Second, school type (i.e., 6-3-3 system vs. 6-6 system) and choice type (i.e., whether the school students entered is his/her first choice or not) were included in the analysis of this study as potential covariates specific to the Japanese education system, but they did not explain individual differences in development of both event centrality and socioemotional well-being during the 3 years of high school life. Although the Japanese government is currently promoting the 6-6 system, which does not require major changes in the school environment and high school entrance exams, to prevent students' maladjustment (Ministry of Education, Culture, Sports, Science and Technology in Japan, 2013), it may not be an evidencebased policy based on the findings of this study. Other covariates (e.g., improving the quality of the high school environment; Iimura \& Kibe, 2020) may need to be investigated in future studies to consider desirable interventions and educational policies that support students' socioemotional well-being.

\section{Conclusions}

To our knowledge, no research on school transition has directly focused on individual differences in susceptibility to the school transition. The present study provided the first evidence that students clearly differ in the centrality of the transition to high school. Researchers and educators should consider individual differences in the degree of centrality of the transition to the student's identity or life story, because it is closely associated with socio-emotional well-being during school life. 


\section{References}

Awata, S., Bech, P., Yoshida, S., Hirai, M., Suzuki, S., Yamashita, M.,...Oka, Y. (2007). Reliability and validity of the Japanese version of the World Health Organization five well-being index in the context of detecting depression in diabetic patients. Psychiatry and Clinical Neurosciences, 61, 112-119. doi: 10.1111/j.1440-1819.2007.01619.x

Barber, B. K., \& Olsen, J. A. (2004). Assessing the transitions to middle and high school. Journal of Adolescent Research, 19, 3-30. doi: 10.1177/0743558403258113

Benner, A. D. (2011). The transition to high school: Current knowledge, future directions. Educational Psychology Review, 23, 299-328. doi: 10.1007/s10648-011-9152-0

Benner, A. D., \& Graham, S. (2007). Navigating the transition to multi-ethnic urban high schools: Changing ethnic congruence and adolescents' school-related affect. Journal of Research on Adolescence, 17, 207-220. doi: 10.1111/j.1532-7795.2007.00519.x

Benner, A. D., \& Graham, S. (2009). The transition to high school as a developmental process among multiethnic urban youth. Child Development, 80, 356-376. doi: 10.1111/j.14678624.2009.01265.x

Benner, A. D., Boyle, A. E., \& Bakhtiari, F. (2017). Understanding students' transition to high school: Demographic variation and the role of supportive relationships. Journal of Youth and Adolescence, 46, 2129-2142. doi: 10.1007/s10964-017-0716-2

Berenbaum, S. A., Beltz, A. M., \& Corley, R. (2015). The importance of puberty for adolescent development: Conceptualization and measurement. In Advances in Child Development and Behavior (Vol. 48, pp. 53-92). JAI.

Berntsen, D., \& Rubin, D. C. (2006). The centrality of event scale: A measure of integrating a trauma into one's identity and its relation to post-traumatic stress disorder symptoms. Behaviour Research and Therapy, 44, 219-231. doi: 10.1016/j.brat.2005.01.009

Bleidorn, W. (2012). Hitting the road to adulthood: Short-term personality development during a major life transition. Personality and Social Psychology Bulletin, 38, 1594-1608. doi: $10.1177 / 0146167212456707$

Boals, A. (2010). Events that have become central to identity: Gender differences in the centrality of events scale for positive and negative events. Applied Cognitive Psychology, 24, 107-121. doi: 10.1002/acp.1548

Duncan, T. E., Duncan, S. C., Stryker, L. A., Li, F., \& Alpert, A. (1999). An introduction to 
latent variable growth curve modelling. Mahwah, NJ: Erlbaum.

Eccles, J. S., Midgley, C., Wigfield, A., Buchanan, C. M., Reuman, D., Flanagan, C., \& Mac Iver, D. (1993). Development during adolescence: The impact of stage-environment fit on young adolescents' experiences in schools and in families. American Psychologist, 48, 90-101. doi: 10.1037/0003-066X.48.2.90

Facchin, F., Margola, D., Molgora, S., \& Revenson, T. A. (2014). Effects of benefit-focused versus standard expressive writing on adolescents' self-concept during the high school transition. Journal of Research on Adolescence, 24, 131-144. doi: 10.1111/jora.12040

Ge, X., Conger, R. D., \& Elder Jr, G. H. (2001). Pubertal transition, stressful life events, and the emergence of gender differences in adolescent depressive symptoms. Developmental Psychology, 37, 404-417. doi: 10.1037/0012-1649.37.3.404

Gehrt, T. B., Berntsen, D., Hoyle, R. H., \& Rubin, D. C. (2018). Psychological and clinical correlates of the centrality of event scale: A systematic review. Clinical Psychology Review, 65, 57-80. doi: 10.1016/j.cpr.2018.07.006

Iimura, S. (2018). Stress-related growth in Japanese adolescents experiencing high school entrance examinations. Current Psychology, 37, 803-808. doi: 0.1007/s12144-017-95641

Iimura, S. \& Taku, K. (2018). Positive developmental changes after transition to high school: Is retrospective growth correlated with measured changes in current status of personal growth? Journal of Youth and Adolescence, 47, 1192-1207. doi: 10.1007/s10964-0180816-7

Iimura, S. \& Kibe, C. (under review). Highly sensitive adolescent benefits in positive school transitions: Evidence for vantage sensitivity in Japanese high-schoolers. PsyArXiv. doi: $\operatorname{XxXXXXXXXXXXX}$

Lord, S. E., Eccles, J. S., \& McCarthy, K. A. (1994). Surviving the junior high school transifamily processes and self-perceptions as protective and risk factors. Journal of Early Adolescence, 14, 162-199. doi: 10.1177/027243169401400205

Ministry of Education, Culture, Sports, Science and Technology in Japan (2013). Chukoikkann kyouikuseido ni kansuru omona ikentou no seiri. Retrieved from https://www.mext.go.jp/b_menu/shingi/chukyo/chukyo3/045/houkoku/1308954.htm Ministry of Education, Culture, Sports, Science and Technology in Japan (2017). Nihongo 
shidouga hitsuyou na jidouseito no ukeirejoukyoutou ni kansuru chousa (heisei 28 nendo) [Annual report of students with Japanese language supports 2016] Retrieved from http://www.mext.go.jp/b_menu/houdou/29/06/_icsFiles/afieldfile/2017/06/21/1386753.p df

Naka, M. (2008). Psychology of self: An approach to cognitive psychology. Tokyo, Japan: Kaneko Shobo.

Newman, B. M., Newman, P. R., Griffen, S., O’Connor, K., \& Spas, J. (2007). The relationship of social support to depressive symptoms during the transition to high school. Adolescence, 42, 441-459.

Pillemer, D. B. (1998). Momentous events, vivid memories. Cambridge, MA: Harvard University Press.

R Development Core Team. (2017). R: A language and environment for statistical computing. Vienna, Austria. Retrieved from http://www.R-project.org/

Rosseel, Y. (2012). lavaan: An R package for structural equation modeling. Journal of Statistical Software, 48, 1-36.

Schermelleh-Engel, K., Moosbrugger, H., \& Müller, H. (2003). Evaluating the fit of structural equation models: Tests of significance and descriptive goodness-of-fit measures. Methods of Psychological Research Online, 8, 23-74. 
Table 1

Means and Standard Deviations for Event Centrality and Socio-Emotional Well-being

\begin{tabular}{lccccccccc}
\hline & \multicolumn{2}{c}{ Time 1 } & \multicolumn{2}{c}{ Time 2 } & \multicolumn{2}{c}{ Time 3 } & \multicolumn{2}{c}{ Time 4 } \\
\cline { 2 - 9 } & Mean & $(S D)$ & Mean & $(S D)$ & Mean & $(S D)$ & Mean & $(S D)$ \\
\hline $\begin{array}{l}\text { Event centrality } \\
\quad \text { 10th grade }\end{array}$ & 2.77 & $(1.06)$ & 2.81 & $(1.10)$ & 2.86 & $(1.09)$ & 2.85 & $(1.08)$ \\
11th grade & 2.91 & $(1.19)$ & 3.13 & $(1.10)$ & 3.12 & $(1.12)$ & 3.12 & $(1.16)$ \\
12th grade & 2.50 & $(0.94)$ & 3.01 & $(1.10)$ & 2.87 & $(1.15)$ & 2.81 & $(1.09)$ \\
Socio-emotional well-being & & & & & & & & \\
$\quad$ 10th grade & 2.69 & $(1.10)$ & 2.88 & $(1.01)$ & 2.77 & $(1.08)$ & 2.83 & $(0.96)$ \\
11th grade & 2.76 & $(1.13)$ & 3.16 & $(1.08)$ & 3.06 & $(1.03)$ & 3.14 & $(1.04)$ \\
12th grade & 2.16 & $(1.04)$ & 2.87 & $(1.12)$ & 2.04 & $(1.38)$ & 3.00 & $(0.96)$ \\
\hline
\end{tabular}


Table 2

Fit Statistics Comparing Models Without Slope, With Linear Slope, and With Quadratic Slope

\begin{tabular}{lcccccc}
\hline Models & CFI & RMSEA & SRMR & AIC & $\chi^{2}(d f)$ & $\Delta \chi^{2} \operatorname{diff}(\Delta d f)$ \\
\hline Event centrality & & & & & & \\
$\quad$ No slope (Only intercept) & .95 & .06 & .06 & 21767.02 & $141.09(27)^{* * * *}$ & - \\
Linear slope & .98 & .06 & .04 & 21718.85 & $74.92(18)^{* * *}$ & $-66.17(-9)^{* * * *}$ \\
Quadratic slope & $N A$ & $N A$ & $N A$ & $N A$ & $N A$ & $N A$ \\
Socio-emotional well-being & & & & & & \\
No slope (Only intercept) & .88 & .09 & .08 & 22321.60 & $240.55(27)^{* * *}$ & - \\
Linear slope & .94 & .08 & .06 & 22229.37 & $130.32(18)^{* * *}$ & $-110.23(-9)^{* * *}$ \\
Quadratic slope & $N A$ & $N A$ & $N A$ & $N A$ & $N A$ & $N A$ \\
\hline
\end{tabular}

Note . CFI = comparative fit index, RMSEA = root mean square error of approximation, $\mathrm{SRMR}=$ standardized root mean square residual, $\mathrm{AIC}=$ Akaike information criterion, $\Delta \chi^{2}$ diff $=$ chisquare difference tests (e.g., chi-square value of the linear model minus chi-square value of the no slope model), $N A=$ not available because results did not converge, $-=$ not available because of the baseline model.

$* * * p<.001$ 
Table 3

Estimated Parameters of Univariate Multi-Group Latent Growth Curve Models

\begin{tabular}{|c|c|c|c|c|c|c|c|c|c|c|c|c|}
\hline & \multicolumn{6}{|c|}{ Intercept } & \multicolumn{6}{|c|}{ Linear Slope } \\
\hline & $\begin{array}{c}\text { Mean } \\
\text { (Fixed effects) }\end{array}$ & $(S E)$ & $p$ & $\begin{array}{c}\text { Variance } \\
\text { (Random effects) }\end{array}$ & $(S E)$ & $p$ & $\begin{array}{c}\text { Mean } \\
\text { (Fixed effects) }\end{array}$ & $(S E)$ & $p$ & $\begin{array}{c}\text { Variance } \\
\text { (Random effects) }\end{array}$ & $(S E)$ & $p$ \\
\hline \multicolumn{13}{|c|}{ Event centrality } \\
\hline 10th grade & 2.75 & $(0.03)$ & $<.001$ & 0.68 & $(0.05)$ & $<.001$ & 0.04 & $(0.01)$ & $<.001$ & 0.02 & $(0.01)$ & .002 \\
\hline 11th grade & 2.72 & $(0.04)$ & $<.001$ & 0.81 & $(0.08)$ & $<.001$ & 0.06 & $(0.02)$ & $<.001$ & 0.04 & $(0.02)$ & .008 \\
\hline 12 th grade & 2.92 & $(0.05)$ & $<.001$ & 0.84 & $(0.11)$ & $<.001$ & 0.06 & $(0.02)$ & .003 & 0.05 & $(0.02)$ & .038 \\
\hline \multicolumn{13}{|c|}{ Socio-emotional well-being } \\
\hline 10th grade & 2.80 & $(0.03)$ & $<.001$ & 0.66 & $(0.05)$ & $<.001$ & 0.03 & $(0.01)$ & .012 & 0.03 & $(0.01)$ & $<.001$ \\
\hline 11th grade & 2.72 & $(0.04)$ & $<.001$ & 0.65 & $(0.08)$ & $<.001$ & 0.05 & $(0.02)$ & $<.001$ & 0.01 & $(0.02)$ & .405 \\
\hline 12th grade & 2.53 & $(0.05)$ & $<.001$ & 0.63 & $(0.10)$ & $<.001$ & 0.17 & $(0.02)$ & $<.001$ & 0.04 & $(0.03)$ & .129 \\
\hline
\end{tabular}


Table 4

Effects of Covariates on the Intercepts and Slopes of Event Centrality and Socio-Emotional Well-Being

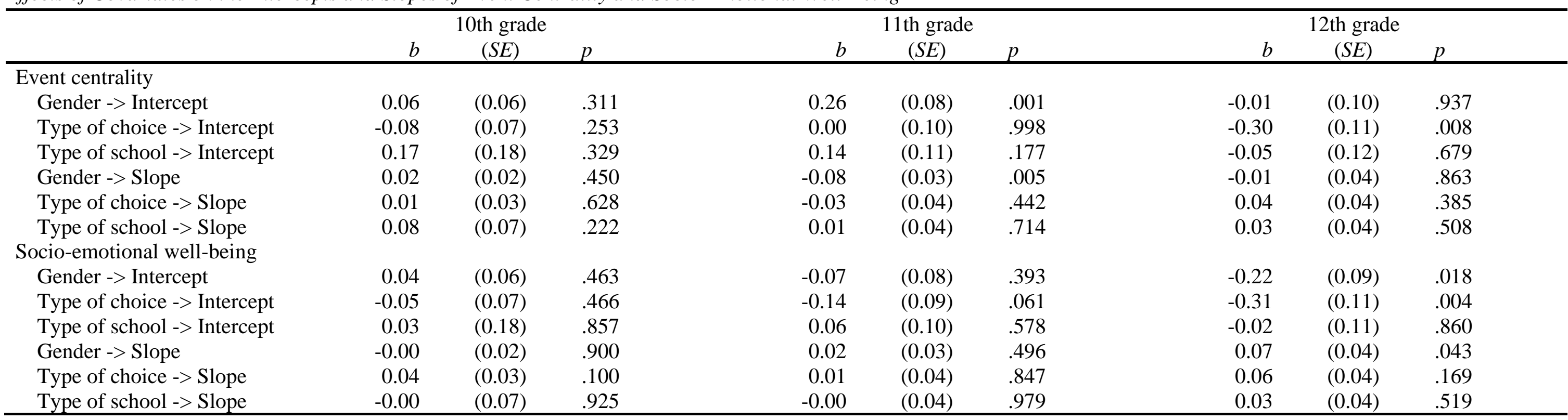

Note. Gender was coded as, $0=$ boys and $1=$ girls. Type of choice was coded as, $0=$ number one choice and $1=$ others. Type of school was coded as, $0=$ integrated junior and

senior high school and $1=$ normative high school. 


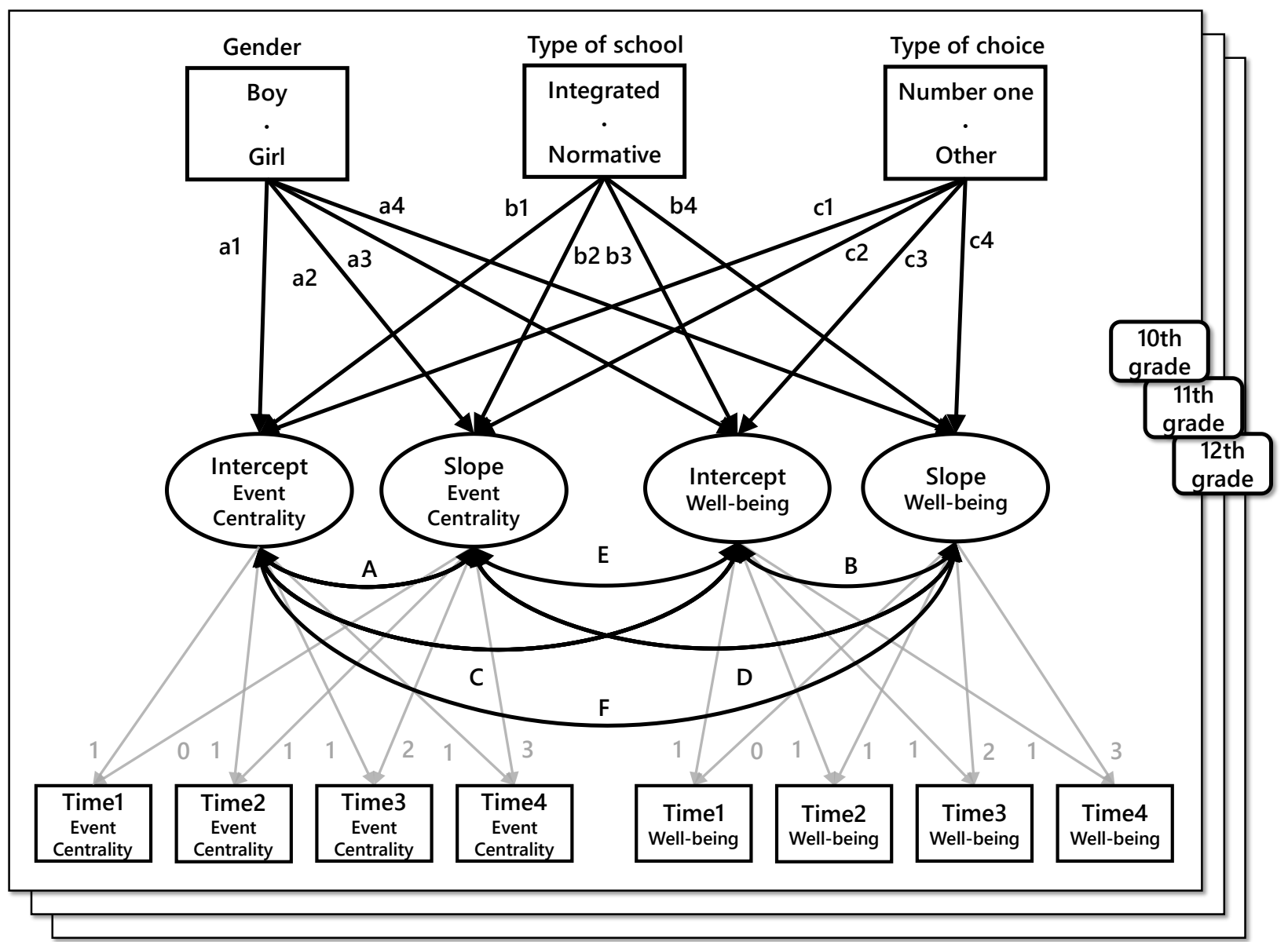

Figure 1. Conditioned bivariate multi-group latent growth curve model. In the figure, "integrated" refers to integrated junior high and senior high schools, whereas "normative," to normative high schools. 


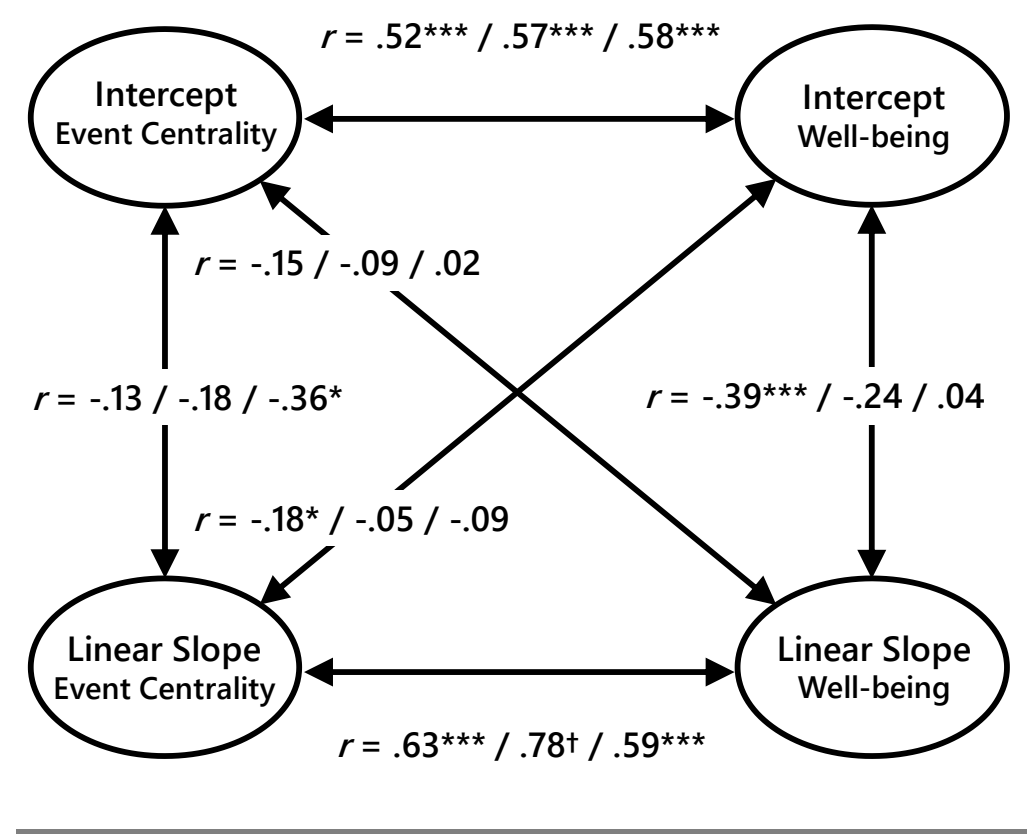

10th grader / 11th grader / 12th grader

Note. ${ }^{* * *} p<.001,{ }^{*} p<.05,+p<.10$

Figure 2. Correlation coefficients between intercepts and slopes for event centrality and socioemotional well-being. 


\section{Appendix}

\section{Event Centrality}

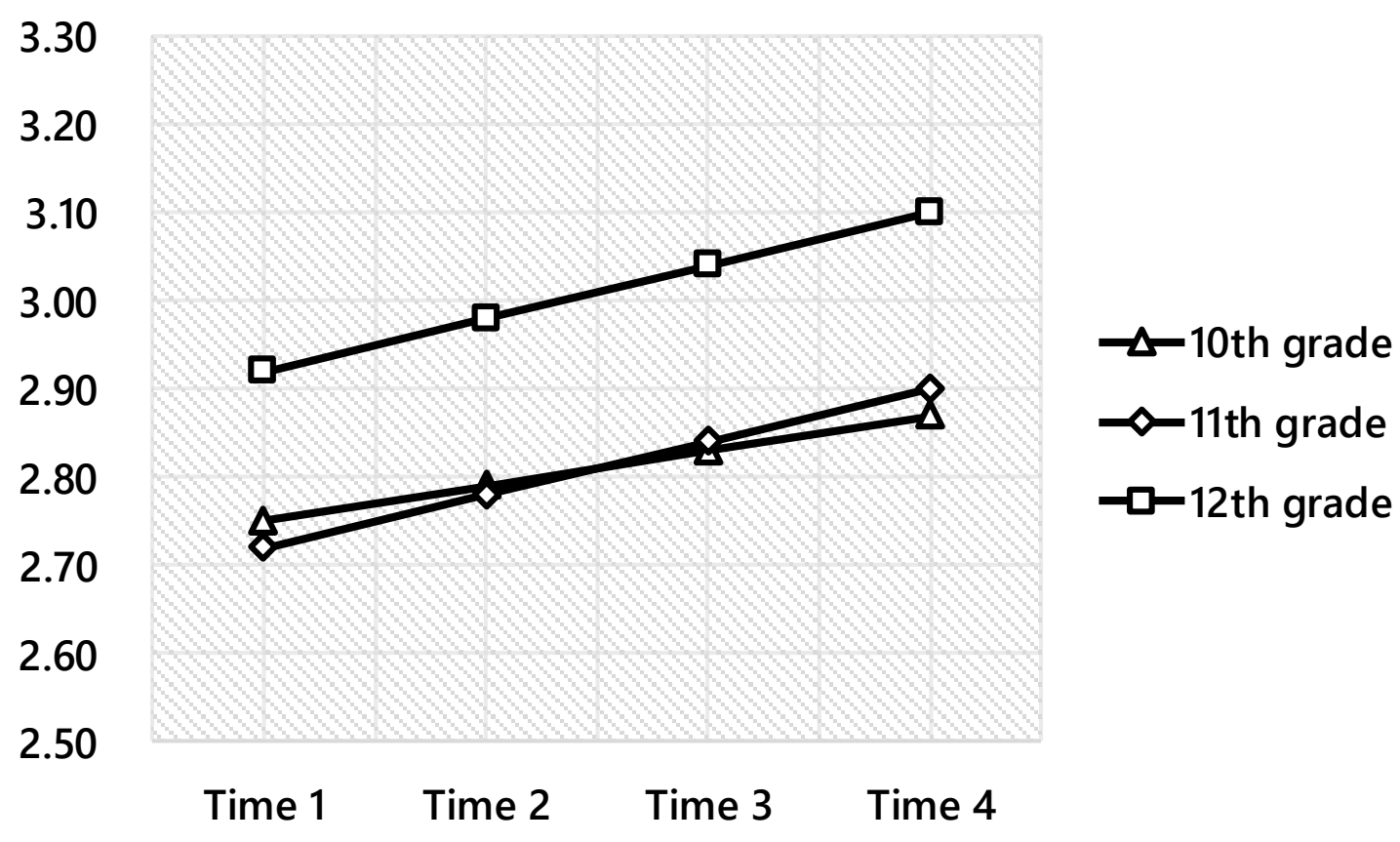

\section{Socio-Emotional Well-Being}

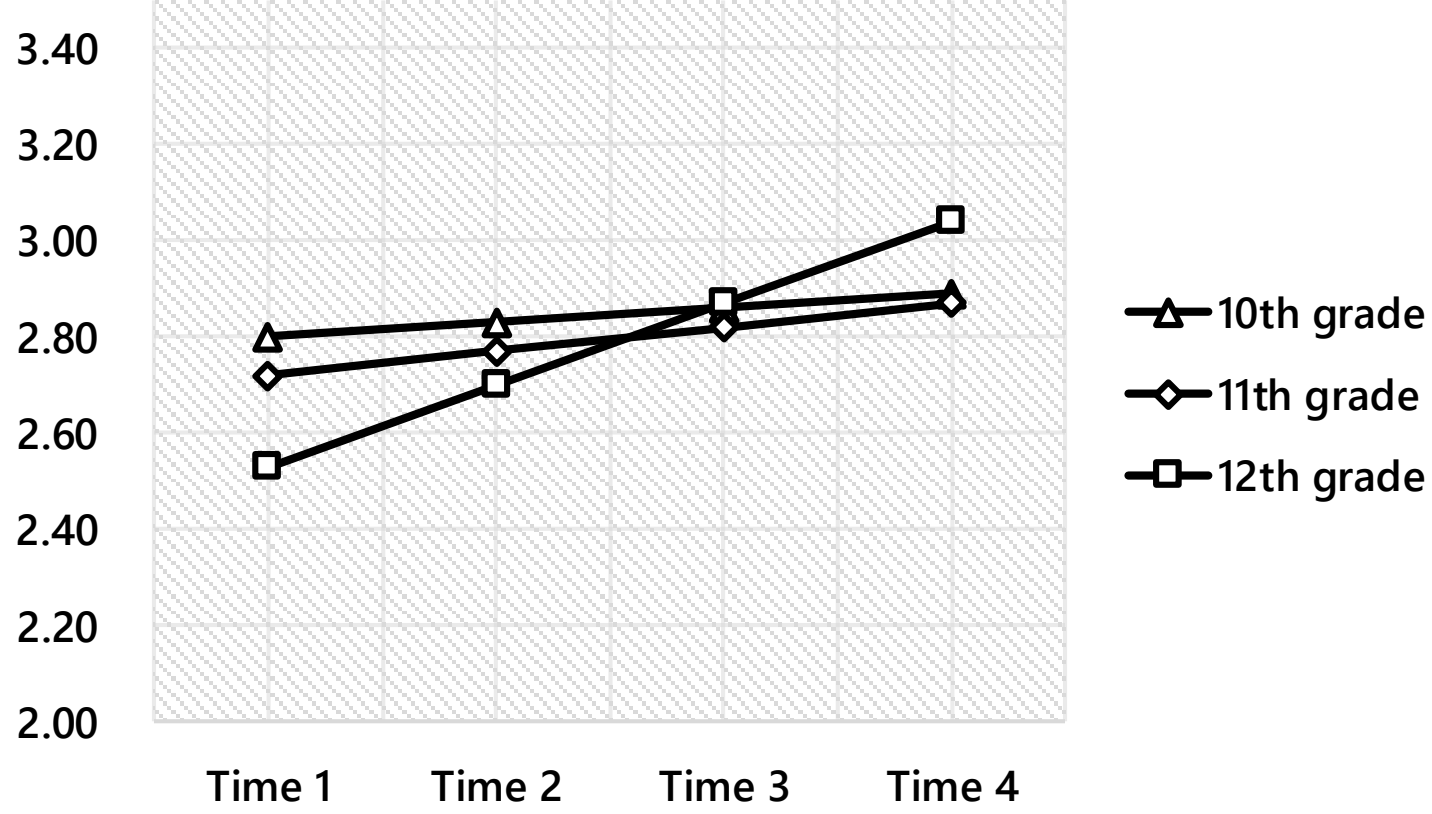

Figure A1. Developmental trajectories of event centrality and socio-emotional well-being. 


\section{Supplementary Materials}

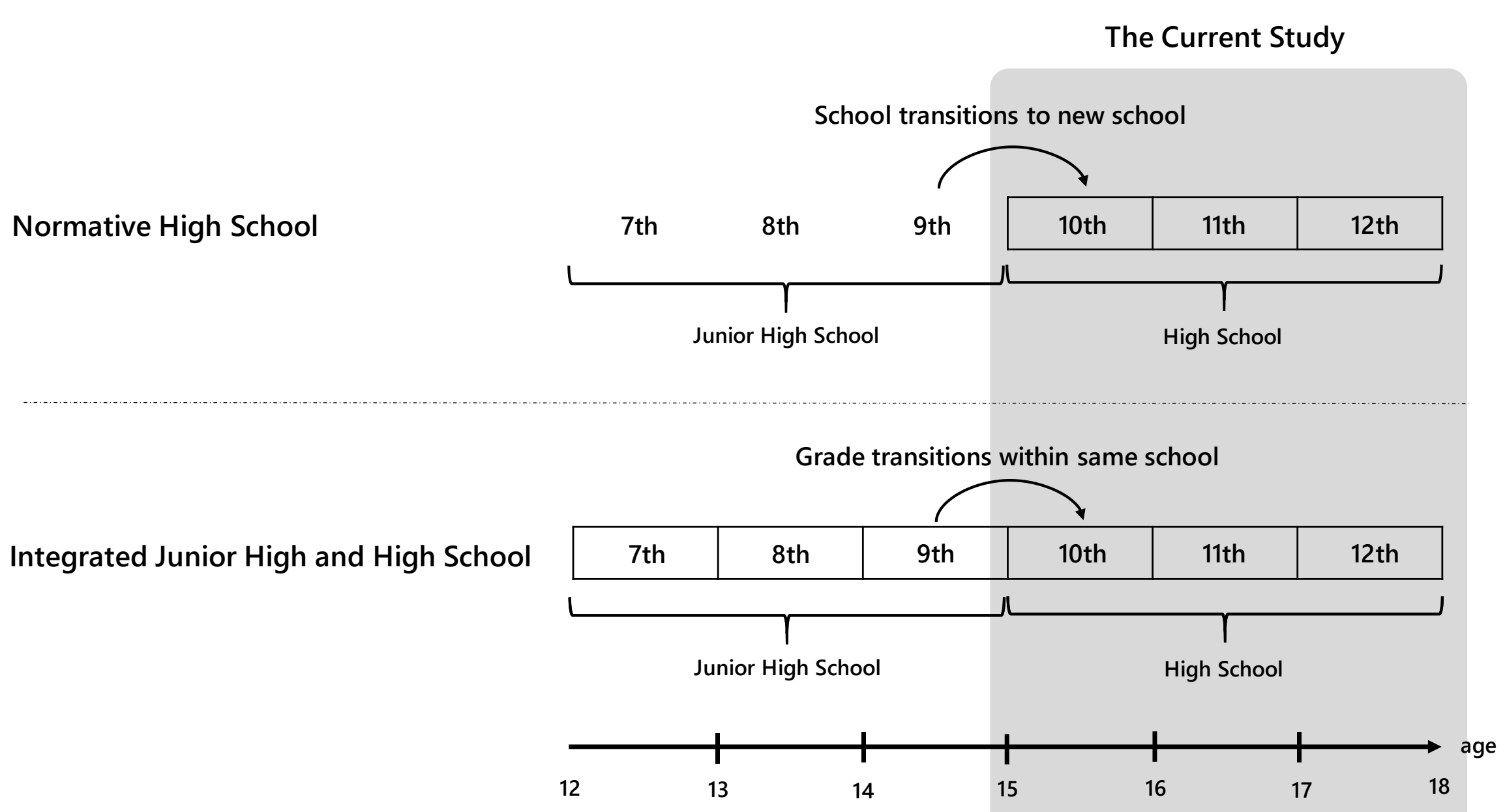

Figure S1. The Relationship between Japanese School Systems and the Current Sample 
Table S1

Longitudinal Factorial Invariance Between Four Time Points in the Factor Structure of Centrality of Event Scale

\begin{tabular}{|c|c|c|c|c|c|}
\hline Model & $\mathrm{BIC}$ & AIC & $\chi^{2}(d f)$ & $\Delta \chi^{2} \operatorname{diff}(d f)$ & $p$ \\
\hline 1: configural invariance & 146479 & 145898 & $3207.0(337)$ & $N A$ & $N A$ \\
\hline 2: weak factorial invariance & 146362 & 145889 & $3233.7(355)$ & $26.7(18)$ & .085 \\
\hline $\begin{array}{l}\text { 3: strong factorial } \\
\text { invariance }\end{array}$ & 146320 & 146320 & $3335.7(373)$ & $101.95(18)$ & $<.001$ \\
\hline
\end{tabular}

Note. Model 1 = invariant factor structure across time; Model $2=$ Model $1+$ invariant factor loadings across time; Model $3=$ Model $2+$ invariant intercepts across time; BIC = Bayesian Information Criterion; AIC $=$ Akaike Information Criterion; $N A=$ not available

As shown in Table S1, BIC supported that model with strong factorial invariance is best fitted to our data $(\mathrm{CFI}=.93$, RMSEA $=.05)$, while AIC and $\Delta \chi^{2}$ difference test supported model with weak factorial invariance $(\mathrm{CFI}=.93, \mathrm{RMSEA}=.05)$; both models showed acceptable model fit. That is, this scale measures "same structure" over four time points.

The output of the weak factorial invariance model with the best fit is shown below.

Group 1 [1]:

Latent Variables:

$\begin{array}{ccccccc}\text { level = } & & & & & \\ \text { ces_Mean_T1 } & 0.613 & 74.968 & 0.008 & 0.993 & 0.613 & 0.583 \\ \text { ces_Mean_T2 } & 0.771 & 24.720 & 0.031 & 0.975 & 0.771 & 0.692 \\ \text { ces_Mean_T3 } & 0.999 & \text { NA } & & & 0.999 & 0.888 \\ \text { ces_Mean_T4 } & 0.947 & \text { NA } & & & 0.947 & 0.867 \\ \text { slope= } & & & & & & \\ \text { ces_Mean_T1 } & 0.935 & 57.125 & 0.016 & 0.987 & 0.935 & 0.889 \\ \text { ces_Mean_T2 } & 0.998 & 112.193 & 0.009 & 0.993 & 0.998 & 0.896 \\ \text { ces_Mean_T3 } & 0.814 & 227.933 & 0.004 & 0.997 & 0.814 & 0.723 \\ \text { ces_Mean_T4 } & 0.789 & 213.455 & 0.004 & 0.997 & 0.789 & 0.722\end{array}$

Covariances:

$$
\begin{array}{r}
\text { level } \sim \\
\text { slope }
\end{array}
$$$$
\text { Estimate Std.Err } \quad \text { z-value } \quad \mathrm{P}(>|\mathrm{z}|) \quad \text { Std.lv } \quad \text { Std.all }
$$

Intercepts:

.ces_Mean_T1
.ces_Mean_T2
.ces_Mean_T3
.ces_Mean_T4

level

Estimate Std.Err $\quad$ z-value $\quad \mathrm{P}(>|\mathrm{z}|) \quad$ Std.lv $\quad$ Std.all

$$
\begin{array}{llll}
-0.517 \quad \mathrm{NA} & -0.517 & -0.517
\end{array}
$$

Estimate Std.Err $\quad$ z-value $\mathrm{P}(>|\mathrm{z}|) \quad$ Std.lv $\quad$ Std.all

$\begin{array}{llllll}2.759 & 0.031 & 88.247 & 0.000 & 2.759 & 2.626\end{array}$

$\begin{array}{llllll}2.772 & 0.033 & 82.776 & 0.000 & 2.772 & 2.487\end{array}$

$\begin{array}{llllll}2.868 & 0.035 & 82.137 & 0.000 & 2.868 & 2.548\end{array}$

$\begin{array}{llllll}2.862 & 0.031 & 93.641 & 0.000 & 2.862 & 2.619\end{array}$

$\begin{array}{lll}0.000 & 0.000 & 0.000\end{array}$



slope
0.000
$0.000 \quad 0.000$

Variances:

\begin{tabular}{|c|c|c|c|c|c|c|}
\hline & Estimate & Std.Err & z-value & $\mathrm{P}(>|\mathrm{z}|)$ & Std.lv & \\
\hline .cs_M_T1 (vare) & 0.447 & 0.016 & 28.714 & 0.000 & 0.447 & 0.405 \\
\hline .cs_M_T2 (vare) & 0.447 & 0.016 & 28.714 & 0.000 & 0.447 & 0.360 \\
\hline .cs_M_T3 (vare) & 0.447 & 0.016 & 28.714 & 0.000 & 0.447 & 0.353 \\
\hline .cs_M_T4 (vare) & 0.447 & 0.016 & 28.714 & 0.000 & 0.447 & 0.375 \\
\hline level & 1.000 & & & & 1.000 & 1.000 \\
\hline slope & 1.000 & & & & 1.000 & 1.000 \\
\hline
\end{tabular}

Group 2 [2]:

Latent Variables:

Estimate Std.Err $\quad$ z-value $\quad \mathrm{P}(>|\mathrm{z}|) \quad$ Std.lv $\quad$ Std.all

$\begin{array}{ccccccc}\text { level= } \\ \text { ces_Mean_T1 } & 0.613 & 74.968 & 0.008 & 0.993 & 0.622 & 0.553 \\ \text { ces_Mean_T2 } & 0.771 & 24.720 & 0.031 & 0.975 & 0.784 & 0.666 \\ \text { ces_Mean_T3 } & 0.999 & \text { NA } & & & 1.015 & 0.890 \\ \text { ces_Mean_T4 } & 0.947 & \text { NA } & & & 0.962 & 0.835 \\ \text { slope= } & & & & & & \\ \text { ces_Mean_T1 } & 0.935 & 57.125 & 0.016 & 0.987 & 0.933 & 0.830 \\ \text { ces_Mean_T2 } & 0.998 & 112.193 & 0.009 & 0.993 & 0.997 & 0.847 \\ \text { ces_Mean_T3 } & 0.814 & 227.933 & 0.004 & 0.997 & 0.812 & 0.713 \\ \text { ces_Mean_T4 } & 0.789 & 213.455 & 0.004 & 0.997 & 0.788 & 0.683\end{array}$

Covariances:

Estimate Std.Err $\quad \mathrm{z}$-value $\mathrm{P}(>|\mathrm{z}|) \quad$ Std.lv $\quad$ Std.all

level $\sim$
slope

Intercepts:

.ces_Mean_T1
.ces_Mean_T2
.ces_Mean_T3
.ces_Mean_T4
level
slope

Variances:

.ces_Mean_T1
.ces_Mean_T2
.ces_Mean_T3
.ces_Mean_T4
level

Estimate Std.Err $\quad$-value $\mathrm{P}(>|\mathrm{z}|) \quad$ Std.lv $\quad$ Std.all

$\begin{array}{cccccc}0.561 & 0.069 & 8.132 & 0.000 & 0.561 & 0.444 \\ 0.524 & 0.055 & 9.496 & 0.000 & 0.524 & 0.378 \\ 0.397 & 0.057 & 7.021 & 0.000 & 0.397 & 0.306 \\ 0.507 & 0.050 & 10.191 & 0.000 & 0.507 & 0.381 \\ 1.032 & 34.080 & 0.030 & 0.976 & 1.000 & 1.000\end{array}$


$\begin{array}{lllllll}\text { slope } & 0.997 & 14.711 & 0.068 & 0.946 & 1.000 & 1.000\end{array}$

Group 3 [3]:

Latent Variables:

Estimate Std.Err $\quad$ z-value $\quad \mathrm{P}(>|\mathrm{z}|) \quad$ Std.lv $\quad$ Std.all

$\begin{array}{ccccccc}\text { level = } & & & & & \\ \text { ces_Mean_T1 } & 0.613 & 74.968 & 0.008 & 0.993 & 0.683 & 0.605 \\ \text { ces_Mean_T2 } & 0.771 & 24.720 & 0.031 & 0.975 & 0.859 & 0.733 \\ \text { ces_Mean_T3 } & 0.999 & \text { NA } & & & 1.113 & 0.963 \\ \text { ces_Mean_T4 } & 0.947 & \text { NA } & & & 1.056 & 0.899 \\ \text { slope= } & & & & & & \\ \text { ces_Mean_T1 } & 0.935 & 57.125 & 0.016 & 0.987 & 1.020 & 0.904 \\ \text { ces_Mean_T2 } & 0.998 & 112.193 & 0.009 & 0.993 & 1.089 & 0.929 \\ \text { ces_Mean_T3 } & 0.814 & 227.933 & 0.004 & 0.997 & 0.887 & 0.768 \\ \text { ces_Mean_T4 } & 0.789 & 213.455 & 0.004 & 0.997 & 0.861 & 0.733\end{array}$

Covariances:

Estimate Std.Err $\quad$ z-value $\quad \mathrm{P}(>|\mathrm{z}|) \quad$ Std.lv $\quad$ Std.all

$$
\begin{array}{r}
\text { level } \sim \\
\text { slope }
\end{array}
$$

Intercepts:

.ces_Mean_T1
.ces_Mean_T2
.ces_Mean_T3
.ces_Mean_T4
level
slope

Variances:

.ces_Mean_T1
.ces_Mean_T2
.ces_Mean_T3
.ces_Mean_T4
level
slope

Estimate Std.Err $\quad \mathrm{z}$-value $\mathrm{P}(>|\mathrm{z}|) \quad$ Std.lv $\quad$ Std.all

$\begin{array}{cccccc}2.812 & 0.055 & 51.231 & 0.000 & 2.812 & 2.494 \\ 3.115 & 0.053 & 59.270 & 0.000 & 3.115 & 2.656 \\ 3.062 & 0.073 & 41.694 & 0.000 & 3.062 & 2.649 \\ 3.063 & 0.052 & 59.444 & 0.000 & 3.063 & 2.607 \\ 0.000 & & & & 0.000 & 0.000 \\ 0.000 & & & & 0.000 & 0.000\end{array}$

\begin{tabular}{cccccc} 
Estimate & Std.Err & z-value & $\mathrm{P}(>|\mathrm{z}|)$ & Std.lv & \multicolumn{2}{l}{ Std.all } \\
0.569 & 0.082 & 6.966 & 0.000 & 0.569 & 0.448 \\
0.531 & 0.070 & 7.604 & 0.000 & 0.531 & 0.386 \\
0.450 & 0.096 & 4.687 & 0.000 & 0.450 & 0.337 \\
0.574 & 0.089 & 6.421 & 0.000 & 0.574 & 0.416 \\
1.241 & 41.335 & 0.030 & 0.976 & 1.000 & 1.000 \\
1.190 & 40.545 & 0.029 & 0.977 & 1.000 & 1.000
\end{tabular}


Table S2

Longitudinal Factorial Invariance Between Four Time Points in the Factor Structure of WHO-5$J$

\begin{tabular}{lccccc}
\hline Model & BIC & AIC & $\chi^{2}(d f)$ & $\Delta \chi^{2} \operatorname{diff}(d f)$ & $p$ \\
\hline $\begin{array}{l}\text { 1: configural invariance } \\
\text { 2: weak factorial invariance }\end{array}$ & 113310 & 112885 & $2249.7(159)$ & $N A$ & $N A$ \\
$\begin{array}{l}\text { 3: strong factorial } \\
\text { invariance }\end{array}$ & 113283 & 112899 & $2287.8(171)$ & $38.15(12)$ & $<.001$ \\
\hline
\end{tabular}

Note. Model 1 = invariant factor structure across time; Model $2=$ Model $1+$ invariant factor loadings across time; Model $3=$ Model $2+$ invariant intercepts across time; BIC = Bayesian Information Criterion; AIC $=$ Akaike Information Criterion; $N A=$ not available

As show in Table 2, BIC supported that model with weak factorial invariance is best fitted to our data $(\mathrm{CFI}=.91$, RMSEA $=.06)$, while AIC and $\Delta \chi^{2}$ difference test supported model with configural factorial invariance $(\mathrm{CFI}=.91$, RMSEA = .06); both models showed acceptable model fit. That is, this scale measures "same structure" over four time points.

The output of the configural factorial invariance model with the best fit is shown below.

Group $1[1]$ :

Latent Variables:

Estimate Std.Err $\quad \mathrm{z}$-value $\mathrm{P}(>|\mathrm{z}|) \quad$ Std.lv $\quad$ Std.all

$\begin{array}{rrrrrrr}\text { level = } \\ \text { health_Mean_T1 } & 1.047 & 32.860 & 0.032 & 0.975 & 1.047 & 0.959 \\ \text { health_Mean_T2 } & 0.839 & 40.377 & 0.021 & 0.983 & 0.839 & 0.812 \\ \text { health_Mean_T3 } & 0.713 & 40.873 & 0.017 & 0.986 & 0.713 & 0.666 \\ \text { health_Mean_T4 } & 0.650 & 36.530 & 0.018 & 0.986 & 0.650 & 0.652 \\ \text { slope = } & & & & & 0.685 & 0.627 \\ \text { health_Mean_T1 } & 0.685 & \text { NA } & & & 0.863 & 0.836 \\ \text { health_Mean_T2 } & 0.863 & \text { NA } & & & 0.963 & 0.939 \\ \text { health_Mean_T3 } & 1.005 & 21.655 & 0.046 & 0.963 & 0.878\end{array}$

Covariances:

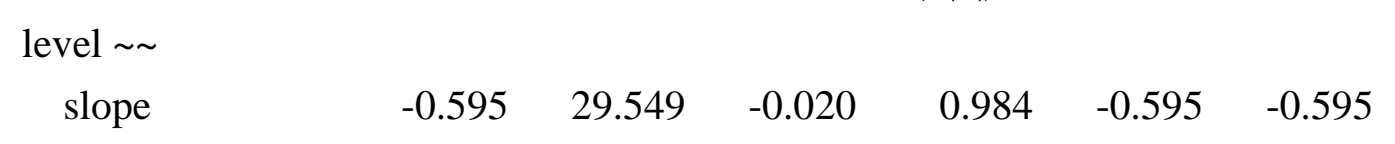

Intercepts:

\begin{tabular}{lrrrrrr} 
& Estimate & Std.Err & z-value & $\mathrm{P}(>|\mathrm{z}|)$ & \multicolumn{3}{c}{ Std.lv Std.all } \\
health_Mean_T1 & 2.754 & 0.033 & 84.171 & 0.000 & 2.754 & 2.521 \\
.health_Mean_T2 & 2.911 & 0.031 & 92.967 & 0.000 & 2.911 & 2.817 \\
.health_Mean_T3 & 2.837 & 0.034 & 84.208 & 0.000 & 2.837 & 2.650 \\
.health_Mean_T4 & 2.872 & 0.028 & 103.025 & 0.000 & 2.872 & 2.880 \\
level & 0.000 & & & & 0.000 & 0.000
\end{tabular}



slope
0.000
0.000
0.000

Variances:

\begin{tabular}{|c|c|c|c|c|c|c|}
\hline & Estimate & Std.Err & z-value & $\mathrm{P}(>|\mathrm{z}|)$ & Std.lv & \\
\hline .hl_M_T1 (vare) & 0.481 & 0.016 & 29.520 & 0.000 & 0.481 & 0.403 \\
\hline .hl_M_T2 (vare) & 0.481 & 0.016 & 29.520 & 0.000 & 0.481 & 0.450 \\
\hline .hl_M_T3 (vare) & 0.481 & 0.016 & 29.520 & 0.000 & 0.481 & 0.419 \\
\hline hl_M_T4 (vare) & 0.481 & 0.016 & 29.520 & 0.000 & 0.481 & 0.484 \\
\hline level & 1.000 & & & & 1.000 & 1.000 \\
\hline slope & 1.000 & & & & 1.000 & 1.000 \\
\hline
\end{tabular}

Group 2 [2]:

Latent Variables:

Estimate Std.Err $\quad$ z-value $\quad \mathrm{P}(>|\mathrm{z}|) \quad$ Std.lv $\quad$ Std.all

\begin{tabular}{|c|c|c|c|c|}
\hline \multicolumn{5}{|l|}{ level = } \\
\hline health_Mean_T1 & 0.790 & NA & 0.790 & 0.687 \\
\hline health_Mean_T2 & 0.950 & NA & 0.950 & 0.880 \\
\hline health_Mean_T3 & 0.895 & NA & 0.895 & 0.810 \\
\hline health_Mean_T4 & 0.828 & NA & 0.828 & 0.763 \\
\hline \multicolumn{5}{|l|}{ slope $=\sim$} \\
\hline health_Mean_T1 & 0.790 & NA & 0.790 & 0.687 \\
\hline health_Mean_T2 & 0.950 & NA & 0.950 & 0.880 \\
\hline health_Mean_T3 & 0.895 & NA & 0.895 & 0.810 \\
\hline health_Mean_T4 & 0.828 & NA & 0.828 & 0.763 \\
\hline
\end{tabular}

Covariances:

Estimate Std.Err $\quad$ z-value $\quad \mathrm{P}(>|\mathrm{z}|) \quad$ Std.lv $\quad$ Std.all

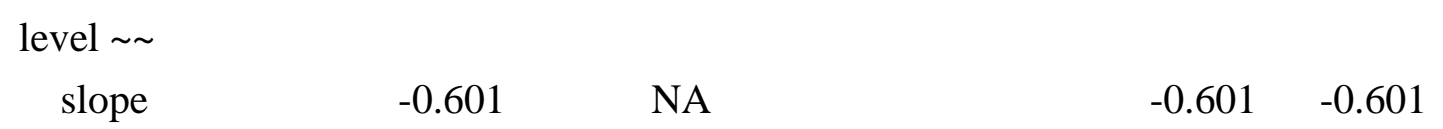

Intercepts:

\begin{tabular}{lrrrrrr} 
& Estimate & Std.Err & z-value & $\mathrm{P}(>|\mathrm{z}|)$ & \multicolumn{3}{c}{ Std.lv Std.all } \\
.health_Mean_T1 & 2.681 & 0.051 & 52.183 & 0.000 & 2.681 & 2.330 \\
.health_Mean_T2 & 2.814 & 0.038 & 73.626 & 0.000 & 2.814 & 2.606 \\
.health_Mean_T3 & 2.759 & 0.048 & 56.978 & 0.000 & 2.759 & 2.494 \\
.health_Mean_T4 & 2.882 & 0.039 & 74.143 & 0.000 & 2.882 & 2.655 \\
level & 0.000 & & & & 0.000 & 0.000 \\
slope & 0.000 & & & & 0.000 & 0.000
\end{tabular}

Variances:

\begin{tabular}{lrrrrrr} 
& Estimate & Std.Err & z-value & $\mathrm{P}(>|\mathrm{z}|)$ & \multicolumn{3}{c}{ Std.lv } & Std.all \\
.health_Mean_T1 & 0.825 & 0.070 & 11.826 & 0.000 & 0.825 & 0.624 \\
.health_Mean_T2 & 0.445 & 0.053 & 8.336 & 0.000 & 0.445 & 0.382 \\
health_Mean_T3 & 0.584 & 0.061 & 9.558 & 0.000 & 0.584 & 0.477 \\
.health_Mean_T4 & 0.631 & 0.050 & 12.505 & 0.000 & 0.631 & 0.536 \\
level & 1.000 & & & & 1.000 & 1.000
\end{tabular}


slope

1.000

$1.000 \quad 1.000$

Group 3 [3]:

Latent Variables:

Estimate Std.Err $\quad$ z-value $\quad \mathrm{P}(>|\mathrm{z}|) \quad$ Std.lv $\quad$ Std.all

$\begin{array}{rrrrrrr}\text { level = } & & & & \\ \text { health_Mean_T1 } & 0.741 & 11.381 & 0.065 & 0.948 & 0.741 & 0.667 \\ \text { health_Mean_T2 } & 0.822 & 12.629 & 0.065 & 0.948 & 0.822 & 0.703 \\ \text { health_Mean_T3 } & 1.040 & 15.979 & 0.065 & 0.948 & 1.040 & 0.722 \\ \text { health_Mean_T4 } & 0.901 & 13.834 & 0.065 & 0.948 & 0.901 & 0.807 \\ \text { slope = } & & & & & & \\ \text { health_Mean_T1 } & 0.741 & 11.387 & 0.065 & 0.948 & 0.741 & 0.667 \\ \text { health_Mean_T2 } & 0.822 & 12.635 & 0.065 & 0.948 & 0.822 & 0.703 \\ \text { health_Mean_T3 } & 1.040 & 15.987 & 0.065 & 0.948 & 1.040 & 0.722 \\ \text { health_Mean_T4 } & 0.901 & 13.841 & 0.065 & 0.948 & 0.901 & 0.807\end{array}$

Covariances:

Estimate Std.Err $\quad$ z-value $\quad \mathrm{P}(>|\mathrm{z}|) \quad$ Std.lv $\quad$ Std.all

level $\sim$
slope

$\begin{array}{llllll}-0.532 & 49.583 & -0.011 & 0.991 & -0.532 & -0.532\end{array}$

Intercepts:

Estimate Std.Err $\mathrm{z}$-value $\mathrm{P}(>|\mathrm{z}|) \quad$ Std.lv $\quad$ Std.all

$\begin{array}{lcccccc}\text {.health_Mean_T1 } & 2.438 & 0.055 & 44.663 & 0.000 & 2.438 & 2.195 \\ \text {.health_Mean_T2 } & 2.886 & 0.053 & 54.532 & 0.000 & 2.886 & 2.468 \\ \text {.health_Mean_T3 } & 2.304 & 0.094 & 24.456 & 0.000 & 2.304 & 1.600 \\ \text {.health_Mean_T4 } & 3.054 & 0.049 & 62.512 & 0.000 & 3.054 & 2.737 \\ \text { level } & 0.000 & & & & 0.000 & 0.000 \\ \text { slope } & 0.000 & & & & 0.000 & 0.000\end{array}$

Variances:

Estimate Std.Err $\quad$-value $\mathrm{P}(>|\mathrm{z}|) \quad$ Std.lv $\quad$ Std.all

$\begin{array}{lcccccc}\text {.health_Mean_T1 } & 0.719 & 0.076 & 9.461 & 0.000 & 0.719 & 0.583 \\ \text {.health_Mean_T2 } & 0.735 & 0.084 & 8.797 & 0.000 & 0.735 & 0.537 \\ \text {.health_Mean_T3 } & 1.062 & 0.164 & 6.477 & 0.000 & 1.062 & 0.512 \\ \text {.health_Mean_T4 } & 0.486 & 0.086 & 5.643 & 0.000 & 0.486 & 0.391 \\ \text { level } & 1.000 & & & & 1.000 & 1.000 \\ \text { slope } & 1.000 & & & & 1.000 & 1.000\end{array}$


Table S3

Measurement Invariance Between Grades in Bivariate Latent Curve Model

\begin{tabular}{lccccc}
\hline Model & BIC & AIC & $\chi^{2}(d f)$ & $\Delta \chi^{2} \operatorname{diff}(d f)$ & $p$ \\
\hline 1: configural invariance & 43274 & 42306 & $160.81(42)$ & $N A$ & $N A$ \\
$\begin{array}{l}\text { 2: weak measurement invariance } \\
\begin{array}{l}\text { 3: strong measurement } \\
\text { invariance }\end{array}\end{array}$ & 43005 & 42181 & $83.58(66)$ & $-77.23(24)$ & 1.000 \\
\hline
\end{tabular}

Note. Model 1 = invariant factor structure across time; Model $2=$ Model $1+$ invariant factor loadings across time; Model 3 = Model $2+$ invariant intercepts across time; BIC = Bayesian Information Criterion; AIC = Akaike Information Criterion; $N A=$ not available

As shown in Table S3, BIC supported that model with strong factorial invariance is best fitted to our data $(\mathrm{CFI}=.98$, RMSEA $=.03)$, while AIC and $\Delta \chi^{2}$ difference test supported model with weak factorial invariance $(\mathrm{CFI}=.98, \mathrm{RMSEA}=.06)$; both models showed acceptable model fit.

The output of the weak factorial invariance model with the best fit is shown below.

Group $1[1]$ :

Latent Variables:

Estimate Std.Err $\quad$ z-value $\quad \mathrm{P}(>|\mathrm{z}|) \quad$ Std.lv $\quad$ Std.all

$\begin{array}{ccccccc}\text { health.level= } & & & & & \\ \text { health_Mean_T1 } & 0.508 & 13.145 & 0.039 & 0.969 & 0.510 & 0.469 \\ \text { health_Mean_T2 } & 0.472 & \text { NA } & & & 0.475 & 0.467 \\ \text { health_Mean_T3 } & 0.801 & 28.806 & 0.028 & 0.978 & 0.805 & 0.740 \\ \text { health_Mean_T4 } & 0.886 & 32.733 & 0.027 & 0.978 & 0.891 & 0.889 \\ \text { health.slope = } & & & & & & \\ \text { health_Mean_T1 } & 0.965 & 25.240 & 0.038 & 0.969 & 0.966 & 0.889 \\ \text { health_Mean_T2 } & 1.196 & 22.860 & 0.052 & 0.958 & 1.198 & 1.177 \\ \text { health_Mean_T3 } & 1.125 & 37.554 & 0.030 & 0.976 & 1.126 & 1.034 \\ \text { health_Mean_T4 } & 1.098 & 39.946 & 0.027 & 0.978 & 1.099 & 1.097 \\ \text { ces.level= } & & & & & & \\ \text { ces_Mean_T1 } & 0.572 & 63.116 & 0.009 & 0.993 & 0.579 & 0.555 \\ \text { ces_Mean_T2 } & 0.596 & 79.806 & 0.007 & 0.994 & 0.604 & 0.541 \\ \text { ces_Mean_T3 } & 0.878 & 69.158 & 0.013 & 0.990 & 0.889 & 0.798 \\ \text { ces_Mean_T4 } & 1.015 & 65.456 & 0.015 & 0.988 & 1.027 & 0.946 \\ \text { ces.slope = } & & & & & & \\ \text { ces_Mean_T1 } & 0.859 & 34.595 & 0.025 & 0.980 & 0.861 & 0.825 \\ \text { ces_Mean_T2 } & 1.078 & 42.458 & 0.025 & 0.980 & 1.081 & 0.967 \\ \text { ces_Mean_T3 } & 0.953 & 41.871 & 0.023 & 0.982 & 0.955 & 0.857 \\ \text { ces_Mean_T4 } & 0.907 & 43.544 & 0.021 & 0.983 & 0.909 & 0.837\end{array}$

Regressions:

Estimate Std.Err $\quad \mathrm{z}$-value $\mathrm{P}(>|\mathrm{z}|) \quad$ Std.lv $\quad$ Std.all

health.level

$\begin{array}{lllll}\text { gender_intgrtd } & 0.103 & \text { NA } & 0.102 & 0.053\end{array}$




$\begin{array}{rcccccc}\text { choice_intgrtd } & 0.168 & \text { NA } & & 0.167 & 0.069 \\ \text { entranc_ntgrtd } & 0.256 & \text { NA } & & 0.255 & 0.052 \\ \text { health.slope } & & & & & & \\ \text { gender_intgrtd } & -0.035 & \text { NA } & & & -0.035 & -0.018 \\ \text { choice_intgrtd } & -0.077 & \text { NA } & & & -0.077 & -0.032 \\ \text { entranc_ntgrtd } & -0.150 & \text { NA } & & & -0.150 & -0.031 \\ \text { ces.level } & & & & & & \\ \text { gender_intgrtd } & 0.158 & 1.176 & 0.134 & 0.893 & 0.156 & 0.081 \\ \text { choice_intgrtd } & -0.001 & 2.327 & -0.001 & 1.000 & -0.001 & -0.001 \\ \text { entranc_ntgrtd } & 0.658 & 4.367 & 0.151 & 0.880 & 0.650 & 0.134 \\ \text { ces.slope } ~ & & & & & & \\ \text { gender_intgrtd } & -0.055 & 9.921 & -0.006 & 0.996 & -0.055 & -0.029 \\ \text { choice_intgrtd } & -0.059 & 2.564 & -0.023 & 0.982 & -0.059 & -0.024 \\ \text { entranc_ntgrtd } & -0.245 & 40.804 & -0.006 & 0.995 & -0.244 & -0.050\end{array}$

Covariances:

Estimate Std.Err $\quad \mathrm{z}$-value $\mathrm{P}(>|\mathrm{z}|) \quad$ Std.lv $\quad$ Std.all

.health_Mean_T1

.ces_Mean_T1

$\begin{array}{llllll}0.142 & 0.029 & 4.940 & 0.000 & 0.142 & 0.224\end{array}$

.health_Mean_T2

.ces_Mean_T2

$\begin{array}{llllll}0.040 & 0.065 & 0.612 & 0.540 & 0.040 & 0.130\end{array}$

.health_Mean_T3

.ces_Mean_T3

$\begin{array}{llllll}0.175 & 0.035 & 4.979 & 0.000 & 0.175 & 0.328\end{array}$

.health_Mean_T4

.ces_Mean_T4

0.052

$0.064 \quad 0.822$

$0.411 \quad 0.052$

0.139

.health.level

$\begin{array}{lcccccc}\text {.health.slope } & -0.743 & 20.707 & -0.036 & 0.971 & -0.743 & -0.743 \\ \text {.ces.level } & 0.898 & 11.584 & 0.078 & 0.938 & 0.898 & 0.898 \\ \text {.ces.slope } & -0.735 & 42.259 & -0.017 & 0.986 & -0.735 & -0.735 \\ \text { health.slope } & & & & & & \\ \text {.ces.level } & -0.484 & 15.526 & -0.031 & 0.975 & -0.484 & -0.484 \\ \text {.ces.slope } & 0.709 & \mathrm{NA} & & & 0.709 & 0.709 \\ \text { ces.level } \sim & & & & & & \\ \text {.ces.slope } & -0.541 & 51.440 & -0.011 & 0.992 & -0.541 & -0.541\end{array}$

Intercepts:

$\begin{array}{lcrrrrr} & \text { Estimate } & \text { Std.Err } & \text { z-value } & \text { P(> }|z|) & \text { Std.lv } & \text { Std.all } \\ \text {.health_Mean_T1 } & 2.757 & 0.118 & 23.343 & 0.000 & 2.757 & 2.537 \\ \text {.health_Mean_T2 } & 2.967 & 0.172 & 17.235 & 0.000 & 2.967 & 2.916 \\ \text {.health_Mean_T3 } & 2.767 & 0.139 & 19.940 & 0.000 & 2.767 & 2.542 \\ \text {.health_Mean_T4 } & 2.769 & 0.144 & 19.203 & 0.000 & 2.769 & 2.763 \\ \text {.ces_Mean_T1 } & 2.605 & 0.135 & 19.350 & 0.000 & 2.605 & 2.497 \\ \text {.ces_Mean_T2 } & 2.659 & 0.183 & 14.528 & 0.000 & 2.659 & 2.381 \\ \text {.ces_Mean_T3 } & 2.511 & 0.163 & 15.433 & 0.000 & 2.511 & 2.254 \\ \text {.ces_Mean_T4 } & 2.393 & 0.156 & 15.319 & 0.000 & 2.393 & 2.205 \\ \text {.health.level } & 0.000 & & & & 0.000 & 0.000 \\ \text {.health.slope } & 0.000 & & & & 0.000 & 0.000 \\ \text { ces.level } & 0.000 & & & & 0.000 & 0.000\end{array}$


.ces.slope

0.000

$0.000 \quad 0.000$

Variances:

\begin{tabular}{lcrrrrr} 
& Estimate & Std.Err & z-value & $\mathrm{P}(>|\mathrm{z}|)$ & \multicolumn{3}{c}{ Std.lv Std.all } \\
.health_Mean_T1 & 0.720 & 0.044 & 16.514 & 0.000 & 0.720 & 0.609 \\
.health_Mean_T2 & 0.221 & 0.083 & 2.647 & 0.008 & 0.221 & 0.213 \\
.health_Mean_T3 & 0.617 & 0.048 & 12.773 & 0.000 & 0.617 & 0.520 \\
.health_Mean_T4 & 0.458 & 0.062 & 7.377 & 0.000 & 0.458 & 0.456 \\
.ces_Mean_T1 & 0.552 & 0.037 & 14.906 & 0.000 & 0.552 & 0.508 \\
.ces_Mean_T2 & 0.422 & 0.071 & 5.925 & 0.000 & 0.422 & 0.339 \\
.ces_Mean_T3 & 0.459 & 0.050 & 9.123 & 0.000 & 0.459 & 0.370 \\
.ces_Mean_T4 & 0.310 & 0.095 & 3.254 & 0.001 & 0.310 & 0.263 \\
.health.level & 1.000 & & & & 0.990 & 0.990 \\
.health.slope & 1.000 & & & & 0.998 & 0.998 \\
.ces.level & 1.000 & & & & 0.976 & 0.976 \\
.ces.slope & 1.000 & & & & 0.996 & 0.996
\end{tabular}

Group 2 [2]:

Latent Variables:

Estimate $\quad$ Std.Err $\quad$ z-value $\quad \mathrm{P}(>|\mathrm{z}|) \quad$ Std.lv $\quad$ Std.all health.level $=\sim$

$\begin{array}{ccccccc}\text { health_Mean_T1 } & 0.508 & 13.145 & 0.039 & 0.969 & 0.434 & 0.377 \\ \text { health_Mean_T2 } & 0.472 & \text { NA } & & & 0.404 & 0.376 \\ \text { health_Mean_T3 } & 0.801 & 28.806 & 0.028 & 0.978 & 0.686 & 0.619 \\ \text { health_Mean_T4 } & 0.886 & 32.733 & 0.027 & 0.978 & 0.758 & 0.700 \\ \text { health.slope = } & & & & & & \\ \text { health_Mean_T1 } & 0.965 & 25.240 & 0.038 & 0.969 & 0.912 & 0.792 \\ \text { health_Mean_T2 } & 1.196 & 22.860 & 0.052 & 0.958 & 1.130 & 1.051 \\ \text { health_Mean_T3 } & 1.125 & 37.554 & 0.030 & 0.976 & 1.062 & 0.960 \\ \text { health_Mean_T4 } & 1.098 & 39.946 & 0.027 & 0.978 & 1.037 & 0.957 \\ \text { ces.level = } & & & & & & \\ \text { ces_Mean_T1 } & 0.572 & 63.116 & 0.009 & 0.993 & 0.622 & 0.555 \\ \text { ces_Mean_T2 } & 0.596 & 79.806 & 0.007 & 0.994 & 0.648 & 0.549 \\ \text { ces_Mean_T3 } & 0.878 & 69.158 & 0.013 & 0.990 & 0.955 & 0.834 \\ \text { ces_Mean_T4 } & 1.015 & 65.456 & 0.015 & 0.988 & 1.103 & 0.960 \\ \text { ces.slope = } & & & & & & \\ \text { ces_Mean_T1 } & 0.859 & 34.595 & 0.025 & 0.980 & 0.999 & 0.892 \\ \text { ces_Mean_T2 } & 1.078 & 42.458 & 0.025 & 0.980 & 1.254 & 1.061 \\ \text { ces_Mean_T3 } & 0.953 & 41.871 & 0.023 & 0.982 & 1.108 & 0.968 \\ \text { ces_Mean_T4 } & 0.907 & 43.544 & 0.021 & 0.983 & 1.055 & 0.918\end{array}$

Regressions:

Estimate Std.Err $\quad$ z-value $\quad \mathrm{P}(>|\mathrm{z}|) \quad$ Std.lv $\quad$ Std.all

health.level

$\begin{array}{lcccccc}\text { gender_intgrtd } & 0.268 & 0.117 & 2.291 & 0.022 & 0.313 & 0.169 \\ \text { choice_intgrtd } & 0.206 & \text { NA } & & & 0.241 & 0.106\end{array}$




$\begin{array}{ccccccc}\text { entranc_ntgrtd } & 0.188 & \text { NA } & & 0.219 & 0.087 \\ \text { health.slope } & & & & & & \\ \text { gender_intgrtd } & -0.194 & \text { NA } & & & -0.205 & -0.111 \\ \text { choice_intgrtd } & -0.270 & \text { NA } & & & -0.286 & -0.126 \\ \text { entranc_ntgrtd } & -0.047 & \text { NA } & & & -0.050 & -0.020 \\ \text { ces.level } ~ & & & & & & \\ \text { gender_intgrtd } & -0.300 & 8.192 & -0.037 & 0.971 & -0.276 & -0.149 \\ \text { choice_intgrtd } & -0.105 & 0.763 & -0.137 & 0.891 & -0.096 & -0.043 \\ \text { entranc_ntgrtd } & 0.077 & 6.344 & 0.012 & 0.990 & 0.071 & 0.028 \\ \text { ces.slope } ~ & & & & & & \\ \text { gender_intgrtd } & 0.372 & 7.688 & 0.048 & 0.961 & 0.320 & 0.172 \\ \text { choice_intgrtd } & 0.038 & 6.552 & 0.006 & 0.995 & 0.032 & 0.014 \\ \text { entranc_ntgrtd } & 0.121 & 11.017 & 0.011 & 0.991 & 0.104 & 0.041\end{array}$

Covariances:

Estimate Std.Err $\quad$ z-value $\quad \mathrm{P}(>|\mathrm{z}|) \quad$ Std.lv $\quad$ Std.all .health_Mean_T1 .ces_Mean_T1 $\begin{array}{llllll}0.209 & 0.045 & 4.606 & 0.000 & 0.209 & 0.289\end{array}$ .health_Mean_T2 .ces_Mean_T2 .health_Mean_T3 .ces_Mean_T3 $\begin{array}{llllll}0.044 & 0.065 & 0.677 & 0.498 & 0.044 & 0.122\end{array}$ .health_Mean_T4 .ces_Mean_T4 $\begin{array}{llllll}0.122 & 0.076 & 1.612 & 0.107 & 0.122 & 0.251\end{array}$ .health.level .health.slope .ces.level .ces.slope .health.slope .ces.level .ces.slope .ces.level .ces.slope

$\begin{array}{rrrrrc}-0.515 & 19.012 & -0.027 & 0.978 & -0.662 & -0.662 \\ 0.689 & 7.121 & 0.097 & 0.923 & 0.768 & 0.768 \\ -0.519 & 35.968 & -0.014 & 0.988 & -0.543 & -0.543 \\ & & & & & \\ -0.268 & 16.988 & -0.016 & 0.987 & -0.268 & -0.268 \\ 0.599 & 4.828 & 0.124 & 0.901 & 0.562 & 0.562 \\ & & & & & \\ -0.740 & 55.920 & -0.013 & 0.989 & -0.602 & -0.602\end{array}$

Intercepts:

\begin{tabular}{lcrrrrr} 
& Estimate & Std.Err & z-value & $\mathrm{P}(>|\mathrm{z}|)$ & \multicolumn{3}{c}{ Std.lv Std.all } \\
.health_Mean_T1 & 2.710 & 0.085 & 31.891 & 0.000 & 2.710 & 2.353 \\
.health_Mean_T2 & 2.909 & 0.094 & 30.795 & 0.000 & 2.909 & 2.706 \\
.health_Mean_T3 & 2.716 & 0.108 & 25.254 & 0.000 & 2.716 & 2.453 \\
.health_Mean_T4 & 2.809 & 0.094 & 29.915 & 0.000 & 2.809 & 2.592 \\
.ces_Mean_T1 & 2.477 & 0.089 & 27.912 & 0.000 & 2.477 & 2.213 \\
.ces_Mean_T2 & 2.582 & 0.101 & 25.469 & 0.000 & 2.582 & 2.184 \\
.ces_Mean_T3 & 2.634 & 0.099 & 26.625 & 0.000 & 2.634 & 2.302 \\
.ces_Mean_T4 & 2.731 & 0.101 & 27.156 & 0.000 & 2.731 & 2.378 \\
.health.level & 0.000 & & & & 0.000 & 0.000 \\
.health.slope & 0.000 & & & & 0.000 & 0.000 \\
.ces.level & 0.000 & & & & 0.000 & 0.000 \\
.ces.slope & 0.000 & & & & 0.000 & 0.000
\end{tabular}


Variances:

\begin{tabular}{lcrrrrr} 
& Estimate & Std.Err & Z-value & P $(>|z|)$ & \multicolumn{3}{c}{ Std.lv Std.all } \\
.health_Mean_T1 & 0.836 & 0.068 & 12.285 & 0.000 & 0.836 & 0.631 \\
.health_Mean_T2 & 0.327 & 0.100 & 3.276 & 0.001 & 0.327 & 0.283 \\
.health_Mean_T3 & 0.604 & 0.062 & 9.812 & 0.000 & 0.604 & 0.492 \\
.health_Mean_T4 & 0.578 & 0.079 & 7.293 & 0.000 & 0.578 & 0.492 \\
.ces_Mean_T1 & 0.627 & 0.062 & 10.091 & 0.000 & 0.627 & 0.501 \\
.ces_Mean_T2 & 0.397 & 0.113 & 3.528 & 0.000 & 0.397 & 0.284 \\
.ces_Mean_T3 & 0.462 & 0.065 & 7.162 & 0.000 & 0.462 & 0.353 \\
ces_Mean_T4 & 0.410 & 0.119 & 3.440 & 0.001 & 0.410 & 0.311 \\
.health.level & 0.698 & 0.569 & 1.227 & 0.220 & 0.954 & 0.954 \\
.health.slope & 0.868 & NA & & & 0.972 & 0.972 \\
.ces.level & 1.153 & 9.142 & 0.126 & 0.900 & 0.976 & 0.976 \\
ces.slope & 1.309 & 5.020 & 0.261 & 0.794 & 0.969 & 0.969
\end{tabular}

Group 3 [3]:

Latent Variables:

Estimate Std.Err $\quad$ z-value $\quad \mathrm{P}(>|\mathrm{z}|) \quad$ Std.lv $\quad$ Std.all

health.level =

$\begin{array}{ccccccc}\text { health_Mean_T1 } & 0.508 & 13.145 & 0.039 & 0.969 & 0.594 & 0.533 \\ \text { health_Mean_T2 } & 0.472 & \text { NA } & & & 0.552 & 0.472 \\ \text { health_Mean_T3 } & 0.801 & 28.806 & 0.028 & 0.978 & 0.937 & 0.670 \\ \text { health_Mean_T4 } & 0.886 & 32.733 & 0.027 & 0.978 & 1.036 & 0.932 \\ \text { health.slope = } & & & & & & \\ \text { health_Mean_T1 } & 0.965 & 25.240 & 0.038 & 0.969 & 0.799 & 0.718 \\ \text { health_Mean_T2 } & 1.196 & 22.860 & 0.052 & 0.958 & 0.991 & 0.847 \\ \text { health_Mean_T3 } & 1.125 & 37.554 & 0.030 & 0.976 & 0.931 & 0.666 \\ \text { health_Mean_T4 } & 1.098 & 39.946 & 0.027 & 0.978 & 0.909 & 0.818 \\ \text { ces.level = } & & & & & & \\ \text { ces_Mean_T1 } & 0.572 & 63.116 & 0.009 & 0.993 & 0.769 & 0.679 \\ \text { ces_Mean_T2 } & 0.596 & 79.806 & 0.007 & 0.994 & 0.803 & 0.690 \\ \text { ces_Mean_T3 } & 0.878 & 69.158 & 0.013 & 0.990 & 1.182 & 1.010 \\ \text { ces_Mean_T4 } & 1.015 & 65.456 & 0.015 & 0.988 & 1.365 & 1.184 \\ \text { ces.slope = } & & & & & & \\ \text { ces_Mean_T1 } & 0.859 & 34.595 & 0.025 & 0.980 & 1.130 & 0.998 \\ \text { ces_Mean_T2 } & 1.078 & 42.458 & 0.025 & 0.980 & 1.419 & 1.220 \\ \text { ces_Mean_T3 } & 0.953 & 41.871 & 0.023 & 0.982 & 1.254 & 1.071 \\ \text { ces_Mean_T4 } & 0.907 & 43.544 & 0.021 & 0.983 & 1.193 & 1.035\end{array}$

Regressions:

Estimate Std.Err $\quad \mathrm{z}$-value $\mathrm{P}(>|\mathrm{z}|) \quad$ Std.lv $\quad$ Std.all

health.level

$\begin{array}{lllll}\text { gender_intgrtd } & 0.335 & \text { NA } & 0.287 & 0.149 \\ \text { choice_intgrtd } & 0.266 & \text { NA } & 0.228 & 0.101 \\ \text { entranc_ntgrtd } & 0.204 & \text { NA } & 0.174 & 0.077\end{array}$




$\begin{array}{cccccccc}\text { health.slope } ~ \\ \text { gender_intgrtd } & -0.280 & \text { NA } & & & -0.338 & -0.176 \\ \text { choice_intgrtd } & -0.361 & 0.161 & -2.250 & 0.024 & -0.436 & -0.193 \\ \text { entranc_ntgrtd } & -0.062 & \mathrm{NA} & & & -0.075 & -0.033 \\ \text { ces.level } ~ & & & & & & \\ \text { gender_intgrtd } & -0.003 & 0.737 & -0.004 & 0.997 & -0.002 & -0.001 \\ \text { choice_intgrtd } & 0.109 & 10.955 & 0.010 & 0.992 & 0.081 & 0.036 \\ \text { entranc_ntgrtd } & 0.120 & 2.426 & 0.050 & 0.960 & 0.089 & 0.039 \\ \text { ces.slope } ~ & & & & & & \\ \text { gender_intgrtd } & -0.017 & 0.920 & -0.018 & 0.986 & -0.013 & -0.007 \\ \text { choice_intgrtd } & -0.339 & 5.786 & -0.059 & 0.953 & -0.257 & -0.114 \\ \text { entranc_ntgrtd } & -0.127 & 4.013 & -0.032 & 0.975 & -0.096 & -0.042\end{array}$

Covariances:

Estimate Std.Err $\quad \mathrm{z}$-value $\mathrm{P}(>|\mathrm{z}|) \quad$ Std.lv $\quad$ Std.all .health_Mean_T1

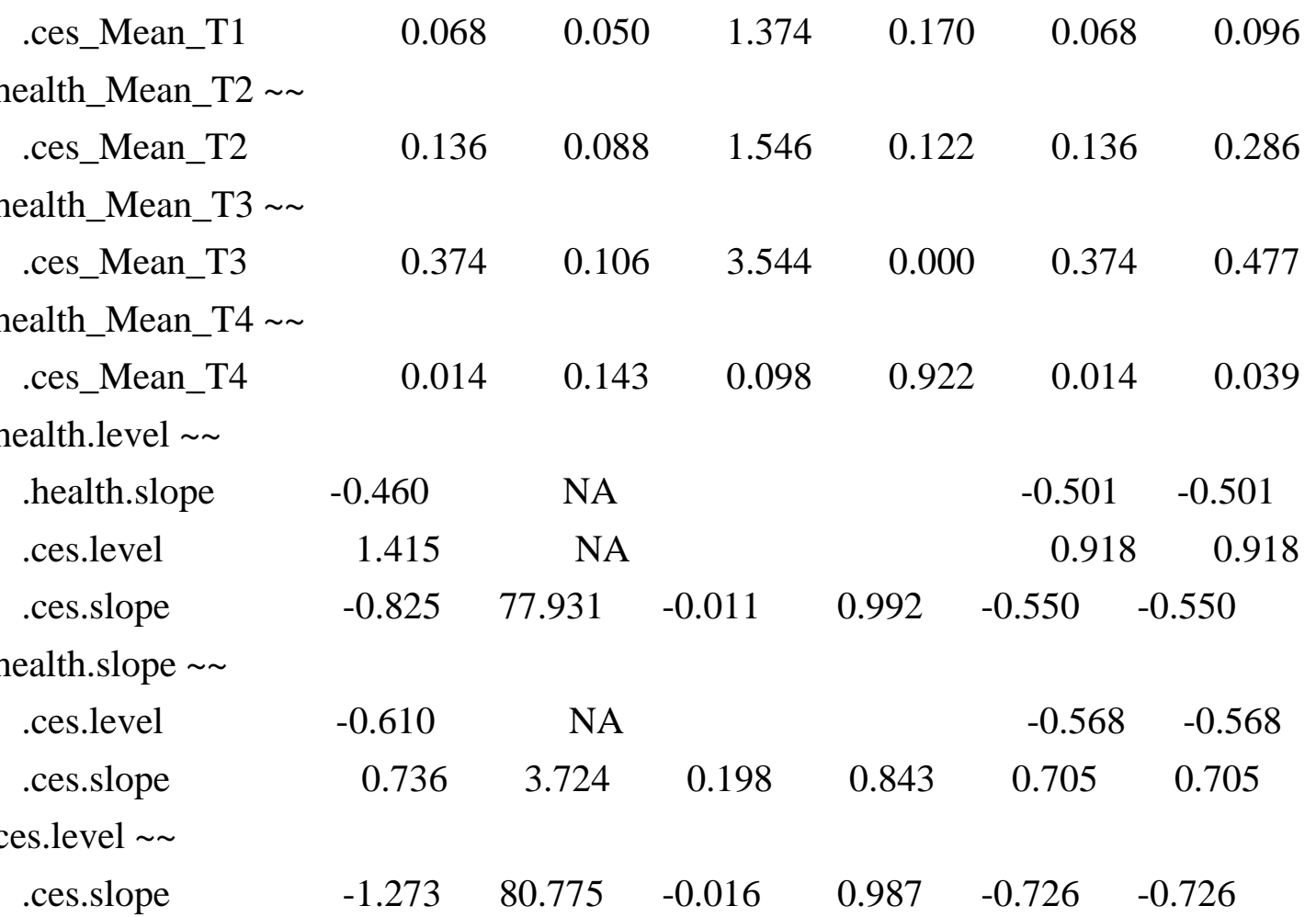

Intercepts:

$\begin{array}{lcrrrrr} & \text { Estimate } & \text { Std.Err } & \text { z-value } & \text { P(>|z|) } & \text { Std.lv } & \text { Std.all } \\ \text {.health_Mean_T1 } & 2.521 & 0.097 & 26.075 & 0.000 & 2.521 & 2.264 \\ \text {.health_Mean_T2 } & 3.048 & 0.116 & 26.349 & 0.000 & 3.048 & 2.605 \\ \text {.health_Mean_T3 } & 2.311 & 0.134 & 17.259 & 0.000 & 2.311 & 1.653 \\ \text {.health_Mean_T4 } & 3.030 & 0.105 & 28.869 & 0.000 & 3.030 & 2.725 \\ \text {.ces_Mean_T1 } & 2.904 & 0.095 & 30.526 & 0.000 & 2.904 & 2.563 \\ \text {.ces_Mean_T2 } & 3.250 & 0.115 & 28.140 & 0.000 & 3.250 & 2.794 \\ \text {.ces_Mean_T3 } & 3.148 & 0.118 & 26.790 & 0.000 & 3.148 & 2.690 \\ \text {.ces_Mean_T4 } & 3.139 & 0.106 & 29.593 & 0.000 & 3.139 & 2.721 \\ \text {.health.level } & 0.000 & & & & 0.000 & 0.000 \\ \text {.health.slope } & 0.000 & & & & 0.000 & 0.000 \\ \text {.ces.level } & 0.000 & & & & 0.000 & 0.000 \\ \text { ces.slope } & 0.000 & & & & 0.000 & 0.000\end{array}$


Variances:

\begin{tabular}{lcccccc} 
& Estimate & Std.Err & z-value & P(>|z|) & \multicolumn{3}{c}{ Std.lv Std.all } \\
.health_Mean_T1 & 0.744 & 0.071 & 10.413 & 0.000 & 0.744 & 0.600 \\
.health_Mean_T2 & 0.654 & 0.116 & 5.632 & 0.000 & 0.654 & 0.477 \\
.health_Mean_T3 & 1.120 & 0.162 & 6.913 & 0.000 & 1.120 & 0.573 \\
.health_Mean_T4 & 0.318 & 0.175 & 1.817 & 0.069 & 0.318 & 0.258 \\
.ces_Mean_T1 & 0.675 & 0.078 & 8.621 & 0.000 & 0.675 & 0.526 \\
.ces_Mean_T2 & 0.347 & 0.134 & 2.578 & 0.010 & 0.347 & 0.256 \\
.ces_Mean_T3 & 0.550 & 0.104 & 5.263 & 0.000 & 0.550 & 0.401 \\
.ces_Mean_T4 & 0.405 & 0.170 & 2.385 & 0.017 & 0.405 & 0.304 \\
.health.level & 1.316 & NA & & & 0.962 & 0.962 \\
.health.slope & 0.640 & NA & & & 0.933 & 0.933 \\
ces.level & 1.806 & 23.247 & 0.078 & 0.938 & 0.997 & 0.997 \\
ces.slope & 1.705 & 54.542 & 0.031 & 0.975 & 0.985 & 0.985
\end{tabular}

